\title{
Control biológico de las plagas de café en Colombia
}

\section{Carmenza Đ. Góngora Botero*}

Laura A. Laiton Jiménez**

*Investigador Científico III, Disciplina de Entomología, Centro Nacional de Investigaciones de Café https://orcid.org/0000-0002-3633-107r

**Asistente de Investigación, Disciplina de Entomología, Centro Nacional de Investigaciones de Café https://orcid.org/0000-0002-3536-0386

Como citar:

Góngora, C. E., \&e Laiton-Jiménez, L. A. (2020). Control biológico en las plagas de café de Colombia. En P. Benavides Machado \&e C. E. Góngora (Eds.), El Control Natural de Insectos en el Ecosistema Cafetero Colombiano (pp. 68-105).

Cenicafé. https://doi.org/10.38141/10791/0001_4 


\section{Definición y métodos de control biológico en el cultivo del café}

I control biológico es el uso de
"enemigos naturales" tales como:
poblaciones de patógenos, parasitoides, predadores, antagonistas $\mathrm{O}$ competidores con el propósito de suprimir una plaga de insectos, disminuyendo su abundancia y el daño que causa al cultivo agrícola que se quiera proteger.

Los métodos de control biológico involucran el uso de enemigos naturales para disminuir los niveles de las poblaciones de las plagas de insectos, entre los que se encuentran (Van Driesche \& Bellows Jr, 1996):

- Conservación

- Introducción de nuevas especies de enemigos naturales

- Aumentación.

\section{Conservación}

Está relacionada directamente con la actividad humana y busca identificar y rectificar influencias negativas que supriman los enemigos naturales, y aumenten los hábitats apropiados para su desarrollo. Se presume que las especies de enemigos naturales coexisten con la plaga y tienen el potencial, si se les da la oportunidad, de suprimirla. Esta presunción es posiblemente verdadera para algunas plagas, específicamente para las endémicas, pero no para aquellas introducidas en donde en el hábitat no se han encontrado y coevolucionado sus enemigos naturales.

En el caso de algunas plagas del café de Colombia, el control biológico por conservación es una estrategia que ha permitido la regulación del minador de la hoja 
del café Leucoptera coffeella. La hembra de este insecto puede depositar 70 huevos en las hojas del café, la larva emerge por la parte inferior del huevo y consumen la epidermis de la hoja penetrando el mesófilo del tejido. Cuando completa su desarrollo, la larva rompe la epidermis de la hoja haciendo un corte en forma de media luna. Se considera una de las principales plagas del cultivo del café Coffea arabica en la región neotropical, ocasionando pérdidas en rendimiento hasta del $80 \%$, en países como Brasil. Sin embargo, en Colombia los ataques han sido esporádicos y las investigaciones realizadas en Cenicafé han permitido identificar siete especies de parasitoides que controlan este insecto: Closterocerus coffeellae, Closterocerus lividus, Zagrammosoma multilineatum, Pnigalio sarasolai, Horismenus sp., Horismenus n. sp., y Apleurotropis n. (David-Rueda et al., 2016).

Los resultados mostraron promedios de infestación del minador inferiores al 2\% y promedios de parasitismo que oscilaron entre $58 \%$ y $89 \%$. El controlador natural más abundante fue $C$. coffeellae. Se recomienda el manejo de esta plaga, a partir de una estrategia de control biológico por conservación (DavidRueda et al., 2016).

\section{Introducción de nuevas especies de enemigos naturales}

En muchos cultivos agrícolas las plagas no nativas o introducidas son un problema, para este tipo de plagas el control natural por conservación no es una opción, debido a que los enemigos naturales están ausentes. En estos casos la introducción de enemigos naturales provenientes de los lugares nativos de la plaga es una necesidad y es una medida que históricamente ha mostrado ser efectiva. La identificación de estos enemigos naturales en los lugares nativos de la plaga se da por observación, luego los especímenes son generalmente recolectados y enviados al país o lugar donde la plaga fue introducida para ser sometidos a apropiadas cuarentenas; estos enemigos son liberados para que cumplan su función.
En el caso de la broca del café, entre los años de 1989 y 1990, se introdujeron al país los parasitoides betílidos Prorops nasuta y Cephalonomia stephanoderis que parasitan larvas de la broca, al igual que Phymastichus coffea, en 1995, que parasita adultos de la broca. Estos tres parasitoides fueron importados de África a Colombia para el control de la broca (Benavides, 2008), dando inicio a su cría masiva y liberación en cafetales afectados; hasta el año 2000 hubo producción y liberación masiva de estos parasitoides. Se liberaron en Colombia alrededor de 2.000 millones de individuos de $C$. stephanoderis (Betrem) y cerca de 500 millones de $P$. nasuta (Waterston); después de 15 años, se recolectaron muestras de café infestado con broca, la que a su vez estaba parasitada con $P$. nasuta, en siete departamentos de Colombia, demostrándose que esta especies logró adaptarse a las condiciones del ecosistema cafetero colombiano, estableciéndose y contribuyendo al control natural de poblaciones de broca en el campo (Maldonado \& Benavides, 2008).

Las introducciones de especies de enemigos naturales tienen ventajas sobre otros tipos de control natural, ya que estos se mantienen y son menos costosos a largo plazo. A medida que los nuevos enemigos naturales son obtenidos, nuevas medidas de conservación son necesarias para que las especies introducidas se adapten y perduren en el medio ambiente y sean efectivas. Este tipo de introducciones requiere conocimiento acerca de la etología tanto de la plaga como del biocontrolador y de los ecosistemas donde se introducen.

Adicionalmente, se han identificado fuerzas negativas que afectan algunas clases de enemigos naturales como son el polvo y cenizas en las hojas (Flaherty \& Huffaker, 1970), elementos altamente abrasivos y desecantes; las zonas cafeteras de muchos países productores de café, especialmente en Centro y Suramérica, incluyendo Colombia, corresponden a zonas con volcanes activos y es interesante destacar 
que las grandes epidemias de arañita roja en la zona cafetera colombiana (Gil et al., 2015) al igual que en Costa Rica (Wille \& Fuentes, 1975) estuvieron asociadas a la emisión de cenizas volcánicas que pudieron disminuir las poblaciones de biocontroladores.

\section{Aumentación}

Cuando los enemigos naturales no están presentes en el ambiente (por ejemplo, en el caso de invernaderos) o su número es tan reducido que no son suficientes para realizar un control efectivo de la plaga, se requiere de una estrategia conocida como "aumentación". Las introducciones pueden darse de dos maneras: liberaciones inoculativas o liberaciones inundativas, también conocidas como liberaciones en masa.

En las liberaciones inoculativas, en las etapas iniciales del cultivo se libera un número reducido de enemigos naturales, con la intención de que se reproduzcan y las progenies lleven a cabo el control de las plagas, por largos períodos de tiempo, a medida que crece el cultivo. Las liberaciones en masa se producen cuando la reproducción de los enemigos naturales es insuficiente para que se realice el control de la plaga y, por lo tanto, es necesario liberar una alta cantidad del enemigo natural en esa primera generación.

En el caso del control de la broca del café con el hongo entomopatógeno Beauveria bassiana, para que el control del insecto sea eficiente y la población de broca se mantenga por debajo del nivel de daño económico al cultivo, se requiere de liberaciones masivas a concentraciones de $2 \times 10^{10}$ esporas/L y aplicaciones de $50 \mathrm{~cm}^{3} / a ́ r b o l$ asperjados a las ramas (Góngora, 2011; Góngora et al., 2009) asegurando la aspersión de un hongo de excelente calidad.

Generalmente, el método de liberación en masa se usa para el control de plagas no endémicas o foráneas, y los principales inconvenientes radican en los costos, la calidad y la efectividad del organismo que se está aplicando. Los costos de producir los biocontroladores van a limitar su uso y la producción va a depender del valor del cultivo, de tal manera que el biocontrolador debe competir económicamente con otros métodos de control. Para que el controlador sea eficiente se requiere de altos estándares de calidad en el proceso de producción de los biocontroladores.

\section{Control biológico en la caficultura colombiana}

Colombia es un país que se caracteriza por su tremenda diversidad biológica, incluyendo biocontroladores y entomopatógenos. Bustillo (2002) realizó una recopilación de las especies de hongos registradas atacando insectos y ácaros en diversos cultivos agrícolas de importancia comercial (yuca, pastos, arroz, maíz, cítricos, frutales, algodón, caña de azúcar, morera, palma africana, algodón, plátano, palma de aceite, tabaco, hortalizas, cacao, fríjol, haba, arveja, maní, trigo, soya, ajonjolí, ornamentales, tomate, zanahoria, ciprés, pino y flores) en diferentes localidades de Colombia.

Esta recopilación resume los hallazgos de varios autores entre 1972 y 1995, y registros encontrados en publicaciones del Instituto Colombiano Agropecuario ICA. El autor reporta la especie $B$. bassiana y Metarhizium anisopliae (Figura 12), como las más frecuentes, las cuales se encuentran atacando 38 y 25 diferentes especies de insectos, respectivamente; le sigue Nomuraea rileyi encontrada en 19 especies, Entomophtoraspp. que ataca 17 especies, y Aschersonia aleyrodis y Verticillium hoy Lecanicillium lecaniatacando 13 especies de insectos. En menor número se encontraron Paecilomyces spp., Myiophagus sp., Cordiceps sp., Hirsutella thompsonii, Isaria sp. y Symmematium. Adicionalmente, atacando unas pocas especies se registraron Conidiobolus coronatus, Sporotrichum, Erynia, Sporodiniella, Podonectria, Cladosporium, Fusarium y Aspergillus. 
Figura 12.

Hongos entomopatogenos

A. Beauveria bassiana y

B. Metarhizium anisopliae creciendo en medio de cultivo

PDA. C. Broca del café
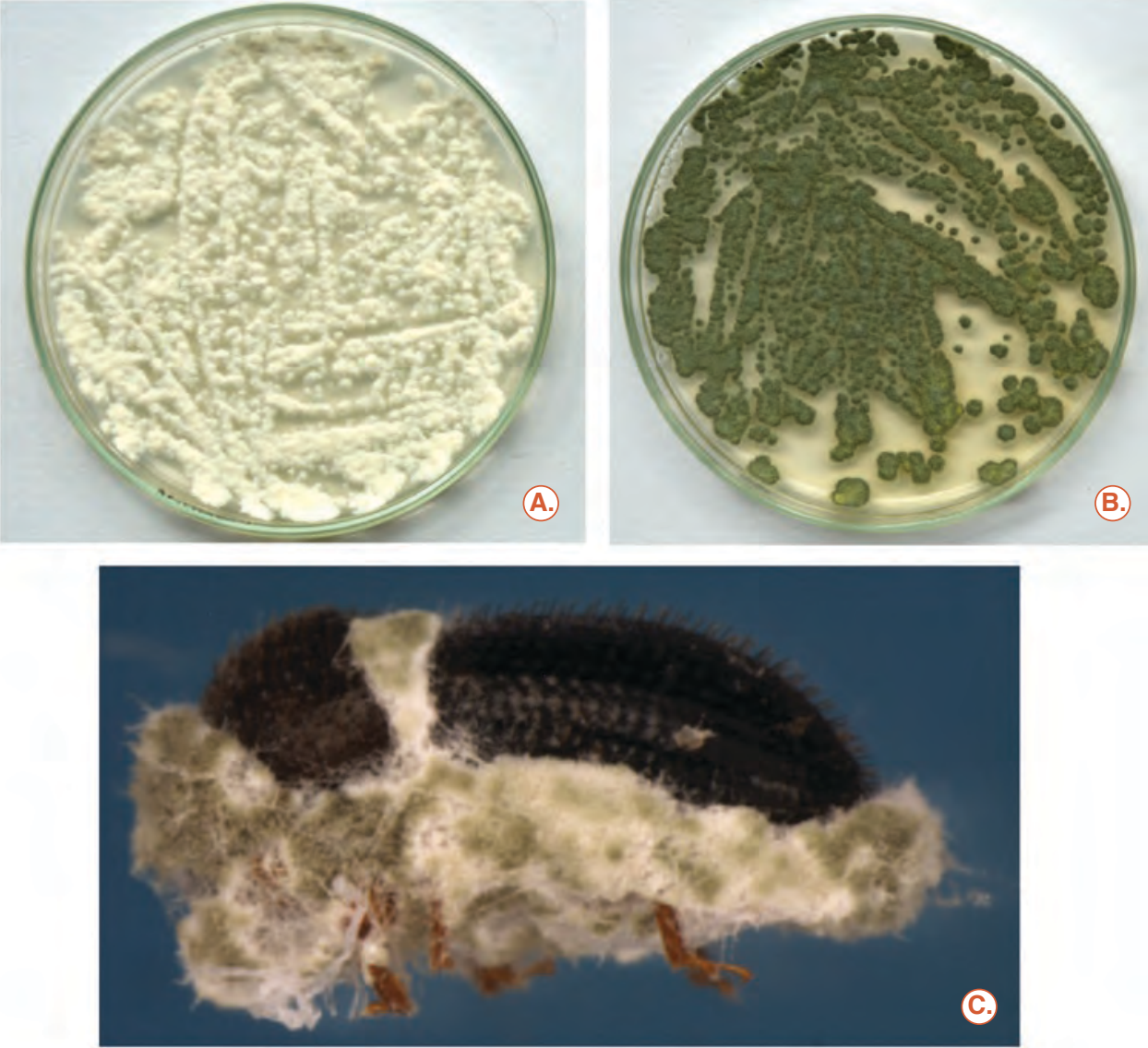

infectada $\operatorname{con} M$. anisopliae

El Manual Cafetero del año 2013 (Constantino et al., 2013) también recopila la información del gran número de parasitoides y depredadores encontrados en el cultivo del café. En donde se reportan al menos 30 depredadores y parasitoides. Estos hallazgos demuestran la amplia diversidad y recursos biológicos que se encuentran en el país. El hecho de contar con tres cadenas montañosas, selva y llanos, un rango amplio de microclimas, con alta humedad relativa y condiciones de temperaturas óptimas para el crecimiento de artrópodos y microorganismos, son características que permiten el desarrollo de esta gran diversidad de biocontroladores.

En la caficultura colombiana existen varios insectos que se consideran plagas, debido a que causan daño económico sobre el cultivo, siendo hoy en día las de mayor importancia la broca del café y las cochinillas de las raíces. Sin embargo, es mayor el número de otros insectos que pudiéndose alimentar en los cafetales y depositar sus huevos, como es el caso del minador de la hoja del café, no ocasionan un daño económico sobre el cultivo y en parte esto se debe a la cantidad de entomopatógenos, depredadores y parasitoides que existen para su control natural en el ecosistema.

\section{Interacción broca del café y B. bassiana}

En Colombia la principal plaga del café $C$. arabica es la broca del café Hypothenemus hampei (Ferrari) (Coleoptera: Scolytinae), que 
fue encontrada atacando frutos en el año 1988, en el departamento de Nariño, y su llegada obligó a Cenicafé a realizar una búsqueda intensiva de controladores naturales de la plaga tanto dentro como fuera del país.

Debido a que en el país la mayoría de los caficultores viven en su finca y su experiencia y tradición en el uso intensivo de insecticidas químicos es reducida; adicionalmente, considerando que las poblaciones de otras plagas potenciales del café y otros cultivos presentes en las fincas no requieren control dada la alta riqueza y abundancia de enemigos naturales, que también pueden ser insectos, y que mantienen el equilibrio biológico en los ecosistemas cafeteros, era una prioridad usar controladores naturales como una alternativa ambientalmente responsable y amigable para el control de la broca.

El primer controlador natural que se encontró atacando la broca del café fue el hongo entomopatógeno B. bassiana (Balsamo) Vuillemin (Posada \& Bustillo, 1994), hoy en día clasificado como B. bassiana (Hypocreales: Clavicipitaceae) (Imoulan et al., 2017). Los hongos patógenos de insectos, o entomopatógenos, penetran, invaden y se multiplican dentro de los insectos. En general, no requieren ser ingeridos por el insecto para causar la enfermedad, ya que pueden penetrar a través de su cutícula. Su crecimiento y desarrollo está limitado principalmente por condiciones medioambientales adversas, especialmente la radiación solar, la baja humedad y las altas temperaturas.

Las unidades de reproducción de estos hongos se conocen como conidias, que usualmente son las que infectan a los insectos. El proceso de infección puede dividirse en tres etapas: 1. Adhesión de las conidias a la cutícula del insecto, y germinación; 2. Penetración de la cutícula del insecto; 3 . Desarrollo del hongo en el interior del insecto, que generalmente termina en la muerte de este (Tanada \& Kaya, 1993).

El hongo $B$. bassiana es usado para el control de un gran número de insectos plaga y es la especie de entomopatógeno comercialmente más utilizada alrededor del mundo (Alves et al., 2002). Las formulaciones consisten en una combinación de ingredientes, de tal forma que las conidias se mantienen estables, efectivas y fáciles de aplicar. La mayoría de las formulaciones de hongos entomopatógenos se producen con materiales inertes como polvos y microtalcos, que deben ser resuspendidos en agua con coadyuvantes, como aceites emulsionables.

El primer reporte de $B$. bassiana infectando naturalmente a la broca del café bajo condiciones de campo fue registrado en 1990, en el departamento de Nariño, donde se recolectaron frutos brocados y brocas adultas muertas que presentaban signos del hongo sobre los insectos: momificación y cubrimiento por el micelio blanco algodonoso y la aparición del mismo en la corona del fruto. La identificación de las cepas de $B$. bassiana encontradas se realizó por medio de claves taxonómicas basadas en características del cultivo, morfología y corroboración de los centros de referencia especializados, dando como resultado la identificación de las cepas de B. bassiana: Cenicafé 069 y Cenicafé 001 (Vélez \& Benavides, 1990).

Con base en aislamientos de hongos obtenidos de brocas desde 1990, se iniciaron entre los años 1995 y 2000 en Colombia, una producción artesanal del hongo por parte de los caficultores y aplicaciones en gran parte de la zona cafetera colombiana(Bustillo, 2007; Góngora etal., 2009). La producción consistió en el crecimiento del hongo en sustrato de arroz usando botellas de vidrio. Después de observar la producción de conidias en las botellas, el hongo era asperjado. La cuantificación de la cantidad de conidias que se producía por botella y el cálculo de las dosis junto con el control de las condiciones asépticas y la contaminación causada por otros hongos era muy complicado. Sin embargo, fue en parte debido a este programa de producción artesanal y aplicaciones, en una época en las que no se producían cepas comerciales, que hoy en día en todos los experimentos realizados en Cenicafé para evaluar la eficacia 
y mortalidad causada por B. bassiana, los controles de los experimentos en los que no se realizan aplicaciones del hongo muestran un control natural cercano al $10 \%$. Por lo tanto, si el hongo no estuviera ejerciendo este efecto sobre las poblaciones de la plaga, las pérdidas ocasionadas en la caficultura colombiana serían mayores (Góngora et al., 2009).

Las aplicaciones de hongo en el campo para el control de brocas sobre frutos en ramas han demostrado que puede inducirse la infección por $B$. bassiana y que los porcentajes de mortalidad aumentan a medida que se eleva el número de aplicaciones (Bustillo et al., 1991).

En todas las evaluaciones que se han realizado, bajo condiciones de campo y con formulaciones de B. bassiana (Bb-9205) del cepario de Cenicafé, se ha establecido el hongo sobre la broca, pero se ha comprobado que sólo es eficaz cuando las conidias entran en contacto con el adulto al tratar de penetrar en la cereza del café. Si el insecto ya penetró al fruto es difícil que el hongo lo pueda infectar (Bustillo, 2002).

Hoy en día $B$. bassiana se considera un controlador natural de la broca, ya que se encuentrainfectando al insecto en condiciones naturales, prácticamente en todos los países donde se ha establecido (Figura 13). El hongo hace parte de la estrategia de manejo integrado de esta plaga y se recomienda su uso por parte de Cenicafé y la FNC; sin embargo, no todas las cepas son iguales, mostrando diferencias a nivel molecular, al igual que su patogenicidad y virulencia sobre la broca del café.

Figura 13.

A. Beauveria bassiana atacando la broca en un fruto de café en el campo y

B.-C. broca del café infectada
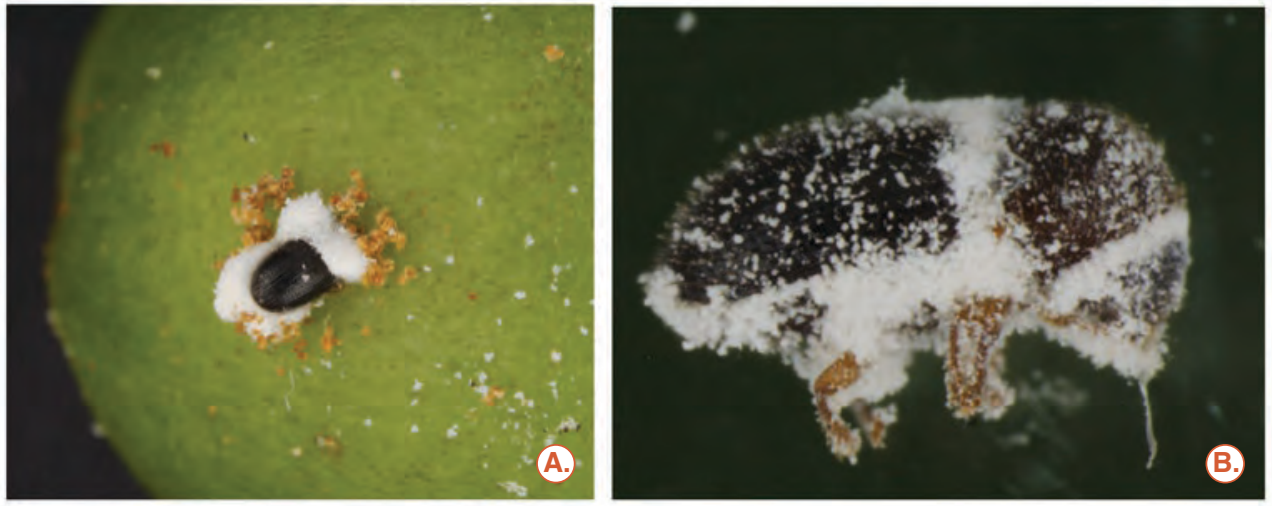

con el hongo B. bassiana.

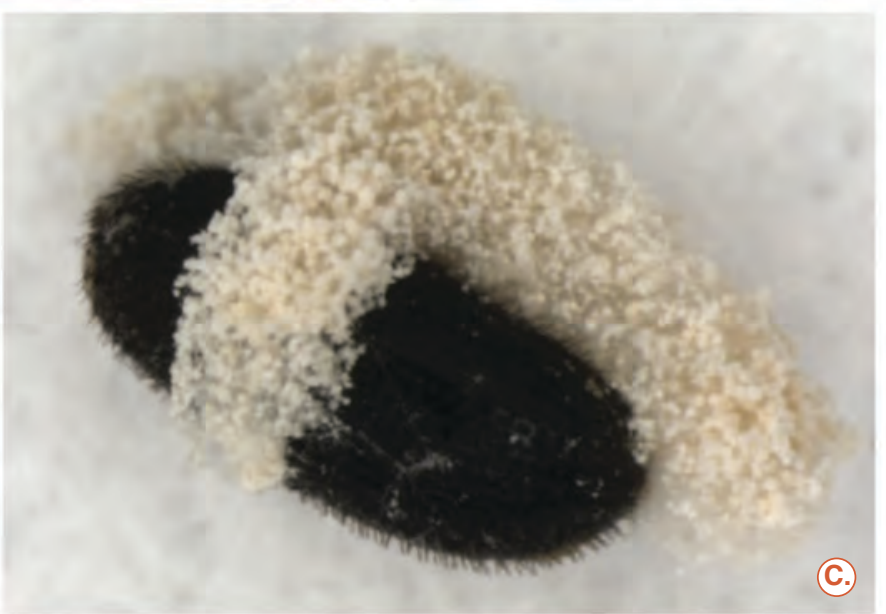


Eficacia de

B. bassiana en el control de la broca del café

Para que el hongo cause alta mortalidad y disminuya el daño económico que ocasiona la broca del café sobre el cultivo, se requiere de aplicaciones inundativas o en masa, en las que ha sido posible, con cepas altamente virulentas, causar mortalidades hasta de $70 \%$, similares a las ocasionadas por los insecticidas químicos (Cárdenas et al., 2007). Sin embargo, para que este tipo de control se presente existen un mínimo de consideraciones a tener en cuenta:

1. Las cepas que se usen para controlar la broca deben ser patogénicas, es decir, deben causar enfermedad, y altamente virulentas, lo que se refiere al grado de patogenicidad, es decir, la cuantificación de la patogenicidad (Shapiro-llan et al., 2005). No todas las cepas son patogénicas ni causan la misma virulencia sobre el insecto plaga, la virulencia se refiere al porcentaje de mortalidad que causa el hongo sobre el insecto.

A nivel de las interacciones existe cierta especificidad entre el entomopatógeno y el insecto atacado, donde no todos serán infectados en el cafetal luego de una aspersión con el hongo. Se conocen varios mecanismos que previenen adhesión y germinación de las conidias a la cutícula de los insectos y existen barreras químicas intrínsecas en el exoesqueleto; un ejemplo interesante son los chinches Pentatómidos, que tienen la habilidad de secretar volátiles a partir de sus glándulas metatoráxicas, en Euschistus heros los compuestos volátiles tipo 4-Oxo-(E)-2hexenal y E)-2-Hexenal tienen propiedades fungistáticas tanto en $M$. anisopliae (Borges \& Aldrich, 1992) como en B. bassiana (Lopes et al., 2015) e inhiben la germinación de esporas.

El grado de especificidad entre el hongo y el insecto está determinado en parte por las características de la cutícula del insecto y sus interacciones con el tubo germinativo y el apresorio que forma el hongo entomopatógeno en el proceso de penetración (Butt et al., 2016). Las fuerzas de adhesión entre las conidias y el insecto van a depender de la naturaleza hidrofílica de la cutícula y las barreras químicas pueden hacer más fuertes o débiles las interacciones. Existen al menos dos proteínas tipo Adhesinas (MAD1 y MAD 2) que facilitan la adhesión del hongo (Wang \& St. Leger, 2007a), pero también se reportan tres tipos diferentes de hidrofobinas (Hyd) (Zhang et al., 2011).

Teóricamente una sola conidia de estos hongos entomopatógenos podría ser capaz de causar la enfermedad del insecto, pero tomaría un largo tiempo ocasionar la muerte. Es debido a esto que en ensayos de inmersión de brocas del café adultas en soluciones de conidias se identifican como cepas altamente patogénicas aquellas que causan una mortalidad de $100 \%$ sobre la broca, cuando se evalúan a concentraciones de $1 \times 10^{7}$ conidias/ $\mathrm{mL}$. La Figura 14, muestra el comportamiento de una cepa con alta virulencia y la mortalidad que causa sobre la broca dependiendo de la concentración de conidias que se evalúan. A su vez las cepas de patogenicidad media o baja requieren una mayor cantidad de conidias para alcanzar la misma mortalidad.

Cuando se evaluaron en el campo las concentraciones de conidias identificadas en laboratorio y, considerando que, en un árbol de café, en una rama con frutos, para obtener un buen cubrimiento debe asperjarse $1 \mathrm{~cm}^{3}$ de solución, se propuso usar $2 \times 10^{7}$ conidias $/ \mathrm{cm} 3$, la mortalidad de $100 \%$ en el laboratorio se lograba con $1 \times 10^{7}$ conidias $/ \mathrm{mL}$. De tal manera que se propuso asperjar $50 \mathrm{~cm}^{3}$ de la solución de $2 \times 10^{7}$ conidias $/ \mathrm{cm}^{3}$ por árbol de café, en árboles con edades entre dos a cuatro años, lo que corresponde a asperjar $1 \times 10^{9}$ conidias/ árbol. Para asperjar esta cantidad de conidias por árbol se requiere preparar soluciones de $2 \times 10^{10}$ conidias/L de agua, siendo esta, la concentración mínima recomendada en el campo y es por esto que las aspersiones del hongo se consideran inundativas. 
Figura 14.

Porcentaje de mortalidad de la broca en pruebas de inmersión y su relación con la concentración de conidias de una cepa con alta patogenicidad. La ecuación Y permite determinar la mortalidad dependiendo de la concentración de conidias.

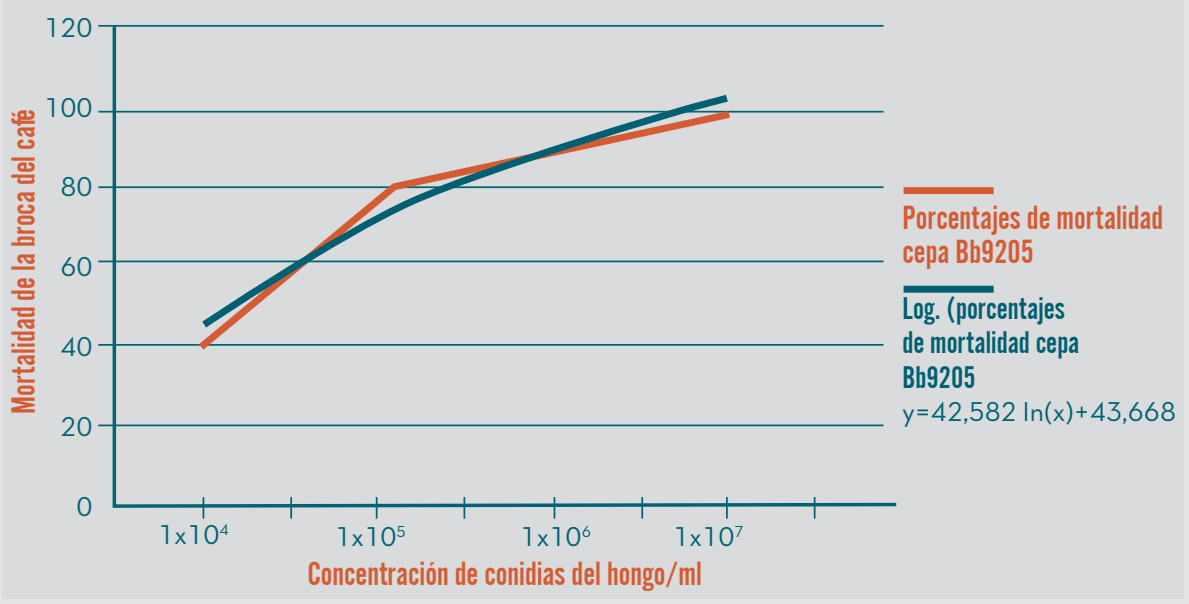

2. Los productos formulados para el control de la broca a base de hongo deben tener una concentración mínima de conidias por gramo de $1 \times 10^{9}$ a partir de cuantificaciones de Unidades Formadoras de Colonia (UFC). De tal manera que, para preparar soluciones de $2 \times 10^{10}$ conidias/L de agua, se requerirían: al menos $2 \mathrm{~g}$, si el producto tiene $1 \times 10^{10}$ conidias/g, y $20 \mathrm{~g}$ de producto si tiene $1 \times 10^{9}$ conidias/g. Entre mayor concentración de conidias tenga el producto, menor cantidad se requerirá para obtener la concentración en el campo (Góngora, 2011; Góngora et al., 2009) y mayor cantidad de hectáreas podrían cubrirse.

3. Adicionalmente, para que el entomopatógeno $B$. bassiana que se emplee en el control de la broca del café sea eficaz, además de la concentración apropiada, debe cumplir con ciertos estándares de calidad (ICA, 2004; Vélez et al., 1997). Debe tener una pureza de al menos 95\% y una germinación mayor al $90 \%$ al cabo de 24 horas. La pureza se refiere a la calidad de las formulaciones de hongos con respecto a presencia de otros microorganismos; se espera que en las formulaciones no existan bacterias ni otro tipo de hongos, lo que implicaría problemas de contaminación de las formulaciones. Estos contaminantes pueden interferir con la germinación de las conidias del hongo, al ser antagonistas, causando inhibición del crecimiento.

La rápida germinación de las conidias es otro atributo de las cepas virulentas, ya que facilita la infección cuando las condiciones climáticas son favorables, inicialmente las conidias comenzarán el proceso de germinación en presencia de agua (alta humedad). Si las conidias germinan uniformemente y en altos porcentajes, se producirán múltiples sitios de penetración en la cutícula de los insectos y esto le permitirá al patógeno colonizar rápidamente el insecto sobreponiéndose a sus defensas y previniendo a su vez la infección con otros saprófitos oportunistas (Altre \& Vandenberg, 2001).

En el proceso de germinación generalmente se produce un apresorio y este genera un punto de penetración que fija el hongo a la cutícula del insecto, causando una presión sobre esta, presión = fuerza $\times$ área, la fuerza generada es relativamente alta ya que el área es relativamente pequeña (Butt et al., 1995). Esto ocasiona distorsión de la cutícula en el sitio de penetración, sugiriendo que una considerable fuerza está siendo aplicada durante la infección. Sin embargo, la presión debe presentarse en diferentes puntos de la cutícula para que sea efectiva y cause los rompimientos de esta. Debido a esto se requieren varias esporas, todas germinando al mismo tiempo para hacer así 
el trabajo que se desea. Adicionalmente, lípidos en el hongo son transportados al apresorio y son convertidos en glicerol, que incrementa la presión hidrostática favoreciendo la penetración mecánica (Wang \& St. Leger, 2007a). Además de la presión física, los hongos cuentan con múltiples copias de genes que se activan durante el proceso de infección y que corresponden a enzimas que degradan la cutícula, es así como se reportan Kinasas proteicas (PKA), además de grupos de enzimas hidrolíticas extracelulares tipo: lipasas, proteasas, quitinasas, fosfolipasa C y catalasas (Schrank \& Vainstein, 2010).

Una vez el hongo penetra la barrera de la cutícula e invade la hemolinfa cambia su estructura, formando blastosporas de pared celular delgada o cuerpos hifales similares a la estructura de una levadura. Las blastosporas se reproducen e invaden el hemocil del insecto y son las que se encargan de atacar el sistema de defensas celular y humoral del insecto, hemocitos y proteínas del sistema inmune (Apholipopherinas, Serpinas, entre otros) (Butt et al., 2016).

Bajo condiciones ambientales favorables: humedad relativa (HR) alta > 90\% y temperaturas óptimas de 20 a $30^{\circ} \mathrm{C}$, el hongo crece fuera del cadáver del insecto, forma los conidióforos y posteriormente presenta la esporulación (Goettel et al., 2005).

Otros puntos clave que favorecen la eficacia de $B$. bassiana para el control de la broca son:

a. La preparación del hongo en el campo debe seguir las recomendaciones consignadas en las etiquetas del producto, las cuales fueron aprobadas por el ICA e indican el modo de preparación y la necesidad de usar un aceite agrícola.

b. La aplicación del hongo debe realizarse en el momento oportuno, cuando los frutos de la cosecha principal se encuentren en el período crítico para ser atacado por la broca (120 días después de la floración principal), que la infestación supere el umbral de acción del $2 \%$ y la broca esté volando, es decir, el
50\% de los adultos estén en posiciones de penetración a los frutos.

c. Para hacer la aspersión se requiere una calibración apropiada de los equipos de aspersión, que permita un buen cubrimiento de conidias sobre los frutos a proteger. Se requiere revisar la fecha de vencimiento del producto, mantenerlo en un lugar fresco y garantizar condiciones de humedad en el ambiente durante las aspersiones, de tal manera que no se expongan las conidias a la radiación directa del sol.

Adicionalmente a $B$. bassiana, existen otros hongos que infectan la broca como es el caso de $M$. anisopliae. Milner \& Lutton (1976) reportan que este hongo está mejor adaptado a condiciones del suelo que $B$. bassiana, empleándose ampliamente en el control de plagas a nivel de la rizosfera, mientras que $B$. bassiana está más asociada a plagas de la parte aérea de las plantas. Por lo tanto, a nivel de control de poblaciones de la broca en frutos del suelo, resulta lógico pensar que $M$. anisopliae podría ser un buen controlador.

Bustillo et al. (1999) y Bernal et al. (1999) realizaron evaluaciones del efecto de aspersiones de B. bassiana cepa Bb-9205 y M. anisopliae Ma-9236 al suelo sobre la broca que emerge de frutos caídos. Estos trabajos fueron ampliados por los desarrollados por Vera et al., (2011) en los que se evaluó la importancia de las aspersiones de hongos sobre frutos infestados con brocas en el suelo.

\section{Interacción otras plagias del café y B. bassiana}

\section{Monalonion sp. y los entomopatógenos}

Monalonion velezangeli es una plaga polífaga, se encontró en café en 1998 en el Huila y su presencia se ha ido expandiendo a las regiones

El Control Natural de Insectos en el Ecosistema Cafetero Colombiano 
cafeteras de Cauca, Nariño y Valle del Cauca, en altitudes superiores a $1.500 \mathrm{~m}$, zonas con baja luminosidad (inferior a 1.400 horas/año) y temperatura promedio inferior a $20^{\circ} \mathrm{C}$ (Ramírez et al., 2008). Las ninfas y adultos del insecto en el cultivo del café atacan los brotes nuevos succionando la savia. El disturbio induce a la planta a una producción continua de follaje, pero con escasa formación de frutos. Un control inadecuado con el uso generalizado de piretroides y organofosforados causa aumento de las poblaciones del insecto, por lo que se hace necesario un manejo integrado de la plaga con énfasis en control con entomopatógenos. En el cepario de Cenicafé existen cepas patógenas de Monalonion.

En lotes afectados por la chinche fueron encontraron enemigos nativos, entre los cuales se evidenció la presencia del hongo Clonostachys sp. atacando un adulto. Las pruebas de laboratorio indican que Clonostachys sp. es un patógeno del insecto. Adicionalmente, se encontraron cepas de $B$. bassiana aisladas del insecto en 1990.

Con el propósito de encontrar un biocontrolador de este insecto, se realizó la siembra de Clonostachys reactivado a partir del cepario y de las cepas de Beauveria. Se sembraron en el medio PDA y después de 15 días se cuantificó la cantidad de conidias que produjeron. Se encontró que, en general, la cepa de Clonostachys presenta pobre esporulación en caja de Petri con medio PDA, debido a que se encontraron producciones de $2 \times 10^{7}$ conidias $/ \mathrm{mL}$ vs $1 \times 10^{8}$ conidias $/ \mathrm{mL}$ producido por B. bassiana. En sustrato de arroz en bolsa la producción de Clonostachys es de tan solo $1,3 \times 10^{7}$ conidias $/ g$, mientras que en Bb9011 es de $6 \times 10^{9}$ conidias/g (Gongora et al., 2020).

El uso de un entomopatógeno está limitado por la cantidad de conidias viables que pueda producir, en el caso de Clonostachys sp. la baja producción de conidias en condiciones controladas no permite su uso en aspersiones en el campo. Debido a esto, se realizaron siembras en medio PDA del hongo $B$. bassiana Bb 9010 y Bb 9011 aislados previamente de Monalonion en los años 90. Se recolectaron insectos de $M$. dissimulatum de cacao y se determinó en el laboratorio por inmersión la virulencia de las cepas a una concentración de $1 \times 10^{7}$ conidias $/ \mathrm{mL}$, manteniendo los insectos en cacao. Se observó mayor virulencia de la cepa Bb 9011 (63\% de mortalidad). Una vez se logró el crecimiento y mantenimiento del $M$. velezangeli usando la planta Cissus verticillata (Vitaceae), se sumergieron 50 insectos durante $30 \mathrm{~s}$, en $100 \mathrm{~mL}$ de la solución de Bb9011, a una concentración de $1 \times 10^{7}$ conidias $/ \mathrm{mL}$, y como control otros 50 insectos se sumergieron en agua. Posteriormente, los insectos se individualizaron y cinco de estos se colocaron en una caja de que contenía tallos y hojas de las plantas. Se mantuvieron nueve cajas con cinco insectos por tratamiento en condiciones controladas a $23^{\circ} \mathrm{C}$ y $80 \%$ de humedad relativa y se revisaron diariamente durante ocho días, contabilizando el número de individuos muertos y el número de ninfas que pasaron a adultos. Se encontró que el hongo causó una mortalidad de $84 \%$ sobre la población del insecto (Figura 3.4). Por último, en jaulas se infestaron plantas de $C$. verticillata con ninfas y adultos de $M$. velezangeli, las plantas infestadas fueron asperjadas con los tratamientos. La unidad experimental fue la planta infestada con seis insectos dentro de la jaula y se evaluó el efecto de la aplicación del hongo a una concentración de $4 \times 10^{10}$ conidias/ $\mathrm{mL}$ sobre las plantas infestadas. El tratamiento contó con diez repeticiones y como control se utilizaron diez plantas infestadas asperjadas con agua. El ANOVA simple mostró diferencias entre los tratamientos, donde la mortalidad promedio de los insectos en el testigo fue de $10 \%$ y en el tratamiento con el hongo fue de 84\%. El siguiente paso será evaluar el control del insecto en el campo (Gongora et al., 2020).

\section{Cochinillas y Metarhizium sp.}

Las cochinillas de las raíces del café son consideradas una plaga endémica; son habitantes naturales que siempre han estado en poblaciones constantes, alimentándose de varias especies de plantas; sin embargo, cuando son dispersadas y se presentan condiciones favorables de clima y suelo, podrían convertirse en plagas del café y afectar 

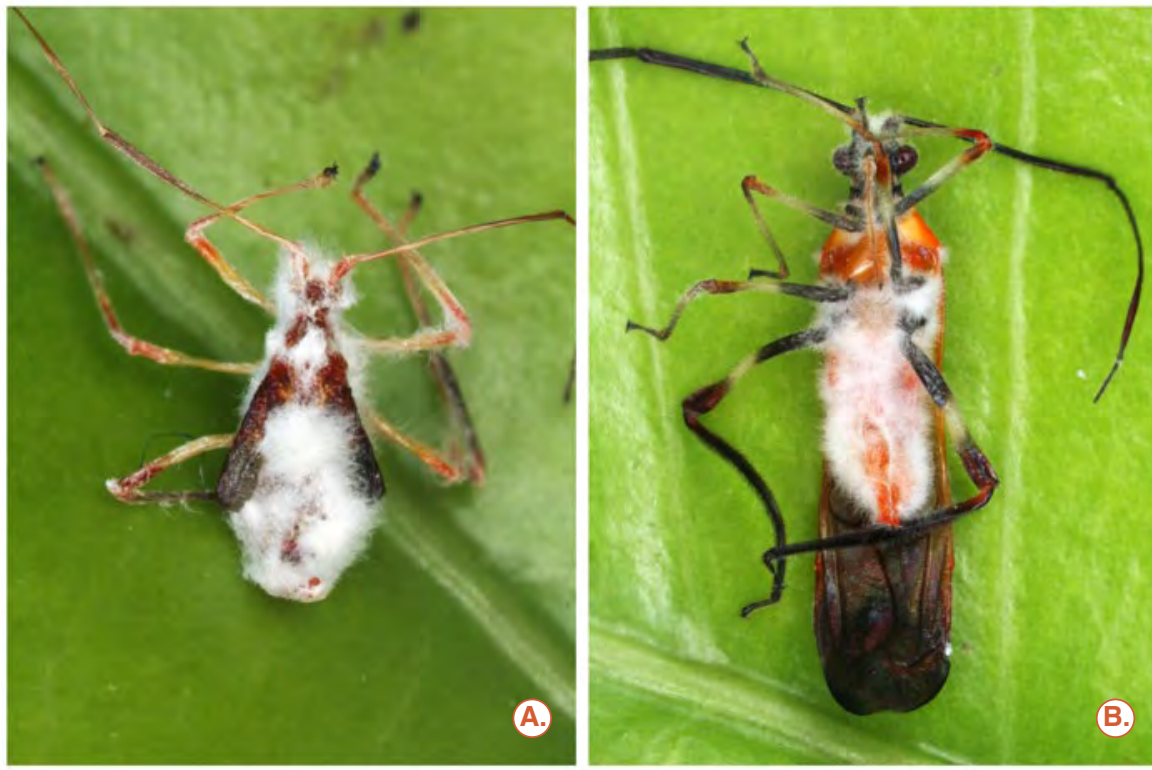

Figura 15.

Individuos de Monalonion velezangeli

infectados con B. bassiana. A. Ninfa; B. Adulto.

la producción. Se localizan en las raíces de los árboles de café, tanto en plantas de almácigos como en plantaciones establecidas. Siendo Puto barberi la especie más abundante (Gil Palacio et al., 2015).

Existen en la naturaleza hongos entomopatógenos controladores de plagas de las raíces. Es así como Metarhizium robertsii J.F. Bisch., Rehner \& Humber (Clavicipitaceae) se reporta como un patógeno que muestra un amplio rango de acción afectando y controlando una gran variedad de insectos (Lomer et al., 2001; Milner, 1997). Además, M. robertsii es la única especie de Metarhizium que se ha encontrado asociada con raíces en el campo, no sólo es rizosfera competente sino también muestra una beneficiosa asociación como endófitos en las raíces de la planta, que da lugar a proliferación de pelos radiculares (Sasan \& Bidochka, 2012).

Considerando el problema causado por las cochinillas de las raíces en café y la interacción que $M$. robertsii puede desarrollar con las raíces del café, defendiendo la planta contra esta plaga, en Cenicafé se han venido ejecutando experimentos con el objetivo de proponer una estrategia para su control basada en el uso de entomopatógenos y específicamente de $M$. robertsii.

Inicialmente, se evaluó en el laboratorio la mortalidad causada por $M$. anisopliae y $M$. robertsii en pruebas de inmersión sobre $P$. barberi, a una concentración de $1 \times 10^{7}$ conidias $/ \mathrm{mL}$ con 12 insectos mantenidos en trozos de Talinum paniculatum y cuatro repeticiones. Al cabo de 12 días se observaron mortalidades entre $75 \%$ y $85 \%$ sin diferencias estadísticas entre los dos hongos. Luego, plantas de almácigo de café con cuatro a seis meses de edad fueron infestadas con cinco hembras oviplenas de P. barberi. A los 60 días de reproducción de la cochinilla, se evaluó el efecto de tres tratamientos: $M$. anisopliae, $M$. robertsii y agua. Para esto, se recolectaron conidias de los hongos producidos en arroz y de cada cepa se preparó una solución de $2 \times 10^{10}$ esporas/L. Cada tratamiento fue aplicado en drench sobre 50 plantas, con una descarga de $50 \mathrm{~cm}^{3} /$ bolsa. Luego de 20 días se examinaron las raíces de cada planta y se determinó la presencia de la plaga y el número de cochinillas por planta. Los resultados mostraron que en las plantas tratadas con agua el porcentaje de infestación fue de 100\% y en promedio se encontraron 25 cochinillas 
por planta. Los tratamientos con aplicación de Metarhizium difirieron del testigo en una prueba $t$ al $5 \%$. La aplicación de $M$. anisopliae disminuyó en $10 \%$ la infestación de la cochinilla y redujo la población en 55\%. La aplicación de M. robertsii disminuyó la infestación en $40 \%$, y la población del insecto disminuyó en $86 \%$. $M$. robertsii se convierte en un buen candidato para ser evaluado en almácigos comerciales (Góngora \& Gil, 2017).

\section{Uso de entomopatógenos y el cepario de Cenicafé}

Cenicafé posee actualmente un cepario o colección de microrganismos entomopatógenos y algunos hongos representativos de la zona cafetera colombiana (Góngora \& Benavides, 2014), como patógenos y hongos aislados del suelo. La gran mayoría de estas cepas han sido aisladas por el personal de Cenicafé en la zona cafetera, a partir de insectos infectados por estos entomopatógenos.

El cepario se inició sus labores en 1990, con aislamientos del hongo B. bassiana (Balsamo) Vuillemin, a partir de brocas recolectadas en frutos brocados, en el municipio de Ancuya, Nariño (Posada, 1997). La historia del cepario original fue descrita por Posada (1997). Desde 1990 hasta el día de hoy, las cepas están codificadas con la primera letra del género y la especie del microorganismo seguido del año de recolección y el número de aislamiento del año de recolección. Por ejemplo, la cepa Bb9001, corresponde al género Beauveria especie $B$. bassiana recolectada en el año 1990, primer aislamiento de ese año.

El objetivo del mantenimiento del cepario es clasificar y preservar microorganismos asociados a insectos plagas y enfermedades del café y otros cultivos de la zona cafetera, además de microrganismos asociados a fertilización del suelo, con el propósito de utilizarlos en estudios de control biológico, fertilización y desarrollo comercial.

La preservación de los entomopatógenos se realiza al almacenar las conidias de los hongos en los siguientes métodos:

- Método aceite mineral: Las conidias del hongo a preservar se siembran en $2 \mathrm{~mL}$ de medio PDA más extracto de levadura al $0,1 \%$, inclinado, contenidos en tubos Pírex de $12 \mathrm{~mL}$. Luego de observar crecimiento y esporulación de los hongos, a los tubos se les adiciona $2 \mathrm{~mL}$ de aceite mineral (Sigma M8410), el cual recubre completamente el hongo y los tubos se almacenan a temperatura ambiente $\left(23^{\circ} \mathrm{C}\right)$ (Figura 3.5).

- Método de nitrógeno líquido: Las conidias se disponen en glicerol al 20\% estéril, en tubos de crio preservación de $2 \mathrm{~mL}$, los cuales posteriormente se congelan en nitrógeno líquido y se almacenan en tanques.

- Glicerol al $20 \%$ y $-20^{\circ} \mathrm{C}$. Las conidias se disponen en glicerol al $20 \%$ estéril, en tubos de crio preservación de $2 \mathrm{~mL}$ y se almacenan en congelación a $-20^{\circ} \mathrm{C}$.

Para evaluar la preservación, los tubos provenientes de nevera $\left(-20^{\circ} \mathrm{C}\right)$ y el tanque de nitrógeno líquido se dejan descongelar, manteniéndolos en hielo y luego se siembran en medio de cultivo sólido (SDA con ácido láctico al $0,2 \%$ ) en cajas de Petri, las siembras se realizan con $20 \mathrm{uL}$ de la cepa preservada o con dos asadas. La solución se distribuye sobre el medio y las cepas se incuban por 15 días, a $26^{\circ} \mathrm{C}$ en oscuridad, o hasta observar un crecimiento micelial que abarque más del $50 \%$ de la caja de Petri. Luego, se evalúa el porcentaje de germinación de las conidias de los hongos.

Cuando las cepas presentan porcentajes de germinación superiores al $70 \%$ las conidias se almacenan nuevamente en glicerol a $-20^{\circ} \mathrm{C}$, nitrógeno líquido y en PDA más aceite mineral. Por cada cepa, en cada medio se almacenan dos tubos. En el caso de que los porcentajes de germinación sean menores al $70 \%$ se realiza una nueva siembra de la cepa a partir de 
estas conidias y nuevamente se dejan incubar durante 15 días, repitiendo los recuentos de germinación, que en estos casos deberían ser de $70 \%$ para proceder a almacenarlas.

Con respecto a los entomopatógenos, el cepario cuenta con 147 aislamientos de B. bassiana recolectados en Colombia y otros países, a partir de broca y otros insectos. Además, cuenta con al menos 40 cepas de Metarhizium que en su mayoría corresponde a $M$. anisopliae (Tabla 3). Estas cepas se vienen evaluando desde hace varios años por sus características de virulencia y más de la mitad han presentado actividad infecciosa contra la broca del café (Góngora et al., 2009). El cepario es una fuente de biocontroladores de diferentes plagas del café y se ha recurrido a esta para el control de la broca y otras plagas del café.

De acuerdo con el Decreto 1375 de 2013 es una obligación registrar las Colecciones Biológicas con un Registro Único de Colecciones (RUC) ante el Von Humboldt. Este registro tiene como objetivo identificar y visibilizar las colecciones existentes debido a que se consideran un invaluable patrimonio, así como para reconocer y posicionar la valiosa información que aporta a la gestión integral y servicios ecosistémicos. Por tal motivo esta colección se encuentra registrada. Sin embargo, el decreto limita las colecciones a actividades con fines científicos, orientadas de manera exclusiva a generar conocimiento e información científica básica, con el fin de descubrir y explicar fenómenos y procesos naturales, sin que incluyan actividades de prospección biológica, aplicación industrial o aprovechamiento comercial.

Es necesario contar con políticas claras que incentiven el uso de las colecciones de microorganismos, el control biológico y la bioprospección. Se requiere que no existan contradicciones en estas políticas e incentivar la investigación, reconocer la inversión y proveer diferentes formas de proteger los recursos biológicos (derechos de propiedad intelectual, regalías por bioprospección), sin que sea necesaria la prohibición de su uso. Las cepas almacenadas en esta colección deberían poder
Tabla 3. Estado actual de las cepas más representativas del cepario de Cenicafé2.

\begin{tabular}{|c|c|}
\hline Género & $\begin{array}{c}\text { Aislamientos } \\
\text { preservados 2017 }\end{array}$ \\
\hline Beauveria bassiana & 147 \\
\hline Beauveria brogniartii & 1 \\
\hline Metarhizium anisopliae & 40 \\
\hline Metarhizium acridium & 1 \\
\hline M. robertsii & 1 \\
\hline Verticillium (= Pochonia) & 5 \\
\hline Lecanicillium & 6 \\
\hline Trichoderma & 7 \\
\hline Paecilomyces & 20 \\
\hline Clonostachys & 1 \\
\hline Phoma & 1 \\
\hline Colletotrichum & 26 \\
\hline Hongos solubilizadores & 64 \\
\hline de fosfatos & 8 \\
\hline Varios & 328 \\
\hline Total & \\
\hline
\end{tabular}

2 Góngora, C. (2017). Informe anual de actividades, Disciplina de Entomología, Cenicafé.

ser usadas por los caficultores para el control de las plagas del café en Colombia.

\section{Uso de parasitoides y depredadores en la caficultura colombiana}

Las poblaciones de insectos, desde el punto de vista de la colonización de hábitats, están divididas en dos grandes grupos: 1. Poblaciones de insectos estrategas-R, los cuales son buenos colonizadores, con alto potencial reproductivo, se dispersanfácilmente y son adaptables e invasores; 2 . Poblaciones de insectos estrategas-K, los cuales son buenos competidores, tienen alta supervivencia y baja tasa de reproducción y baja mortalidad por lo que se consideran estables. La mayoría de las plagas fitófagas de los cultivos agrícolas son estrategas-R. Los enemigos naturales, por ejemplo, los parasitoides y depredadores son principalmente estrategas-K (Nicholls, 2008). 
A su vez, los insectos depredadores son aquellos que capturan y se alimentan de animales vivos, usualmente de otros insectos (Romoser \& Stoffolano, 1998); estos se utilizan dentro de programas de control biológico para regular las poblaciones de plagas herbívoras. Los depredadores forman un grupo diverso con miembros pertenecientes a más de 16 órdenes y aproximadamente 200 familias. Se estima que hay más de 200.000 especies de artrópodos depredadores en el mundo (Sweetman, 1958). Aunque la mayoría de insectos depredadores son generalistas, existen especialistas que consumen una variedad de presas limitada, pertenecientes a una misma familia de insectos. Los insectos depredadores se caracterizan por ser generalmente más grandes que sus presas y tanto los estados inmaduros como los adultos matan y consumen más de una presa para garantizar su desarrollo; sin embargo, algunos resultan más eficaces que otros al momento de controlar plagas agrícolas. El hecho de requerir más de una presa para desarrollarse, incrementa el riesgo de mortalidad del depredador en los diferentes estados inmaduros. El efecto biocontrolador de los depredadores se fundamenta en el hecho de que, tanto los estadíos inmaduros como adultos del depredador, requieren consumir más de una presa para cumplir con sus funciones vitales, en el caso de las larvas o ninfas para completar su ciclo de vida, mientras que el adulto lo utiliza para funciones reproductivas. Caso contrario ocurre con los parasitoides, donde la relación parasitoide - huésped es por lo menos 1:1; es decir, por cada huésped parasitado se asegura el alimento al inmaduro y la formación de mínimo un adulto (Hassel, 1980). Entre los factores que influyen en la frecuencia de consumo y el éxito de un depredador se encuentran la abundancia de la presa, la preferencia por esta y la competencia con otros depredadores (Denoth et al., 2002).

Broca del café. Dentro de los frutos de café brocados se han encontrado insectos parasitoides y algunos depredadores que tienen la habilidad de penetrar por el orificio de entrada que hace la broca en el fruto y buscar sus presas: huevos, larvas y adultos de broca a través de las galerías y túneles.

Laiton et al. (2018) hicieron una revisión de los parasitoides y depredadores que regulan las poblaciones de broca. En África Central, región de origen de la broca se reportan: los parasitoides $P$. nasuta, $C$. stephanoderis (Hymenoptera: Bethylidae) y P. coffea (Hymenoptera: Eulophidae), mencionados previamente. Además de Heterospiluscoffeicola (Hymenoptera: Braconidae) y el depredador Karnyothrips flavipes (Thysanoptera: Phaelothripidae). En el continente americano se han encontrado reportes de los parasitoides Cephalonomia hyalinipennis (Hymenoptera: Bethylidae) en México y Cryptoxilos sp. (Hymenoptera: Braconidae) en Colombia. Entre los depredadores se tienen reportados en Colombia varios insectos que atacan los estados inmaduros y adultos en los frutos del árbol y del suelo. Las especies más importantes reportadas pertenecen a las familias Formicidae (Hymenoptera), Anthocoridae (Hemiptera) y Silvanidae (Coleoptera). En el grupo de los coleópteros, dos especies nativas de Silvanidae, se han registrado dentro de las galerías y túneles en granos infestados de broca (Bustillo et al., 2002; Vera et al., 2008) como Cathartus quadricollis Guerin-Meneville (Reiche, 1854) y Monanus $\mathrm{sp}$. En condiciones de laboratorio, adultos de ambas especies, recolectados en el campo, alcanzaron porcentajes de depredación de larvas y huevos de broca mayores al 60\% (Vera et al., 2008).

En 2013, Constantino reportó a Ahasverus advena (Waltl, 1832) y Europs sp., otras dos especies de Silvanidae, como depredadores de estados biológicos de broca en Colombia (Cenicafé, 2013). Las especies de Silvanidae se caracterizan por ser depredadores de ácaros y pequeños insectos, así como por ubicarse frecuentemente en lugares escondidos. Esta es probablemente la razón por la que se encuentran estas especies dentro de los frutos de café, aprovechando el orificio realizado durante la entrada de la broca, con el fin de buscar refugio y estados inmaduros de la broca como fuente de alimentación (Vera et al., 2008). 
En pruebas de palatabilidad realizadas en Cenicafé con diferentes dietas, se estudió el comportamiento de alimentación y biología de C. quadricollis y $A$. advena, y se concluyó que estas especies no consumen ni se reproducen en almendra molida de café (Cenicafé, 2013). Esto confirma que su presencia en las galerías de la broca del café está relacionada con eventos de depredación de estados inmaduros de broca y no representan riesgos como potencial plaga del café. Recientemente, Follett et al. (2016) evaluaron la capacidad depredadora de adultos de $C$. quadricollis obteniendo $77,5 \%$ de depredación en huevos, 55\% en larvas, 53\% en pupas y $15,5 \%$ en adultos. Laiton et al. (2018) evaluaron la depredación de C. quadricollis y $A$. advena sobre la broca, en condiciones de laboratorio en Cenicafé utilizando granos de café brocados.

Encontraron que tanto los adultos como las larvas de $A$. advena disminuyen significativamente la broca entre $63,2 \%$ y $42,3 \%$ con respecto al testigo, siendo mayor la capacidad depredadora cuando se cuenta con tres individuos por grano brocado. Igualmente, C. quadricollis disminuyó la broca hasta $46,2 \%$ y $69,0 \%$ cuando se liberaron tres adultos y cinco larvas por grano, respectivamente. Estos resultados abren una nueva posibilidad en el manejo integrado de la broca, por lo que los autores plantean evaluar en el campo, en bioensayos de exclusión, la capacidad de estos depredadores para bajar poblaciones de broca. La variable de interés deberá ser la infestación ocasionada por la broca en los frutos de café de las cosechas principales, posterior a la liberación de los depredadores una vez finalice la cosecha inmediatamente anterior.

Otros controladores que han sido evaluados son los nematodos de las familias Steirnernematidae y Heterorhabditidae para el control de los individuos presentes en frutos caídos al suelo (Lara et al., 2004). Al ser mezclado Steinernema colombiense con hongos entomopatógenos como M. anisopliae y B. bassiana, estos podrían ser capaces de transportar conidias al interior del fruto y disminuir la población potencial de broca con capacidad de infestar frutos sanos (Lara et al., 2004).

\section{Chinche de la chamusquina Monalonion velezangeli}

Con respecto a la chinche de la chamusquina del café, en Colombia se han observado en el campo algunos enemigos naturales de ninfas y adultos de $M$. velezangeli, como arañas depredadoras, y con mayor frecuencia, insectos de la familia Reduviidae (Hemiptera) (Giraldo-Jaramillo et al., 2011). Estas chinches son de hábitos polífagos, se alimentan de una amplia variedad de insectos de los órdenes Coleoptera, Lepidoptera y Diptera (Insuasty et al., 2007).

Dentro de los géneros de la familia Reduviidae (Hemiptera) reportados como depredadores de $M$. velezangeli se encuentran Zelus Fabricius, 1803, Arilus Hahn, 1831 y Repipta Stål, 1859 (Giraldo-Jaramillo et al., 2011). Zelus vespiformis Hart, 1987 (Hemiptera: Reduviidae) es una especie Neotropical distribuida desde Centro América al Norte de Suramérica. Las especies de Arilus, al igual que Z. vespiformis, habitan en Centro América y el Norte de Suramérica (Maldonado, 1990; Zhang et al., 2016); siendo el depredador $Z$. vespiformis uno de los más comunes dentro de cafetales del Valle del Cauca y Huila. En Cenicafé se logró estandarizar un método de cría a base de Galleria mellonella y una solución de miel al 30\% diseñado por Gil (Cenicafé, 2016).

Un estudio exploratorio realizado por Laiton (Cenicafé, 2017) permitió realizar una identificación de enemigos naturales de Reduviidae por medio de un muestreo por observación en el campo, en lotes de café ubicados entre 1.200 y $2.000 \mathrm{~m}$ de altitud en los municipios de La Plata, La Argentina, Palestina, Acevedo y Pital del departamento del Huila. Los esfuerzos de muestreo fueron dirigidos a las zonas afectadas por la chinche de la chamusquina y durante la exploración se recolectaron 29 posturas, 216 ninfas y 14 adultos de Reduviidae: entre ellos los géneros Ricolla, Arilus, Castolus y tres especies de Zelus (Figura 16). El 85\% de los individuos se recolectaron en altitudes superiores a los $1.750 \mathrm{~m}$ y tan solo el $15 \%$ entre los 1.200 y 
los $1.700 \mathrm{~m}$ (Figura 17). Los individuos del género Zelus se encontraron sobre árboles del género Citrus (Rutaceae: Sapindales) y sobre café, mientras que Arilus, Castolus y Ricolla se recolectaron solo sobre árboles de café. Los individuos recolectados fueron llevados a Cenicafé donde se establecieron colonias, con el fin de realizar estudios descriptivos: biología y respuesta funcional, que permitan definir la estrategia de control biológico más adecuada para el control de la chinche de la chamusquina.

\section{Cómo mejorar los controladores y el control biológico}

Con el fin de obtener una mayor eficacia de los hongos biocontroladores se ha profundizado en el conocimiento de los mecanismos genéticos que dan a estos hongos sus características de patogenicidad y virulencia. Adicionalmente, se han evaluado las concentraciones y dosis apropiadas de aplicación en el campo, así como el uso de mezclas de cepas y combinación de extractos botánicos. En el caso de los depredadores se hace necesario hacer una selección de estos basados en estudios de biología y ecología, para entender su comportamiento y posibilidades de uso.

\section{Uso de mezclas de cepas de entomopatógenos}

Las mezclas de cepas de entomopatógenos no solo incrementan el espectro de acción, sino que también aseguran su eficacia bajo diferentes condiciones ambientales (Góngora, 2008). Inglis et al. (1997) determinaron que una mezcla de $B$. bassiana, por su resistencia a bajas temperaturas, y $M$. anisopliae por su resistencia a altas temperaturas, podría ser más efectiva para el control de saltamontes que las cepas usadas individualmente.

Cruz et al. (2006) evaluaron el efecto del uso de mezclas de cepas en la virulencia de $B$. bassiana frente a la broca del café. Las cepas se caracterizaron genéticamente. El análisis agrupó los aislamientos en tres grupos genéticos. Se realizaron pruebas de virulencia de las cepas frente a la broca en el laboratorio, empleando concentraciones de $1 \times 10^{6}$ conidias $/ \mathrm{mL}$. La virulencia obtenida para cada cepa fluctuó entre $57,5 \%$ y $89,91 \%$. Al mezclar conidias de cepas similares genéticamente no se observaron diferencias significativas en la patogenicidad. Al mezclar cepas con virulencias superiores al 85\% y diferentes genéticamente, se obtuvieron mortalidades significativamente bajas (57\%), mientras que al mezclar cepas con virulencia inferior al $80 \%$ y diferentes genéticamente

Figura 16.

Arilus gallus depredador de Monalonion.

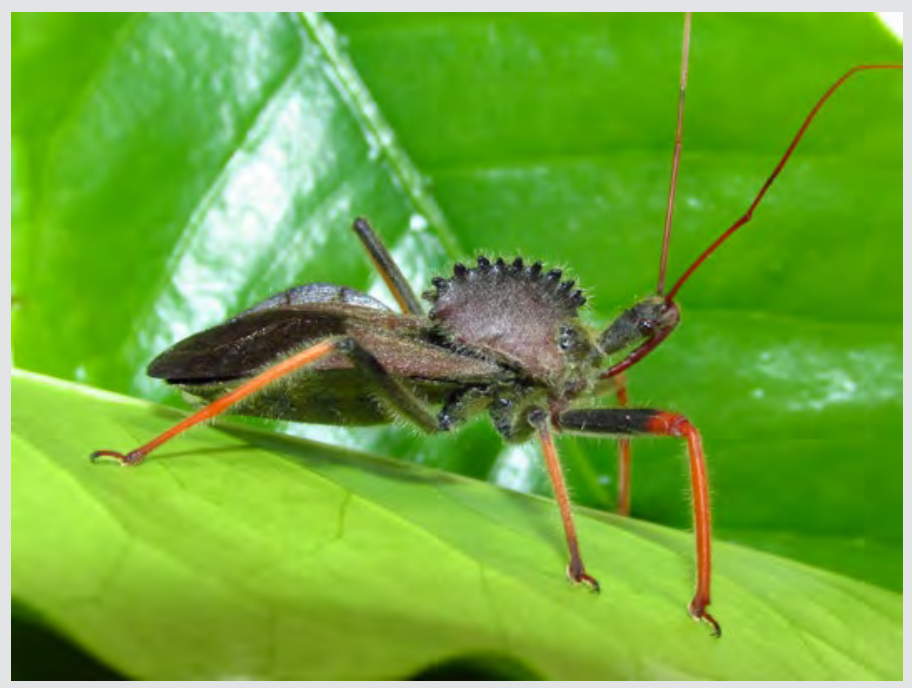




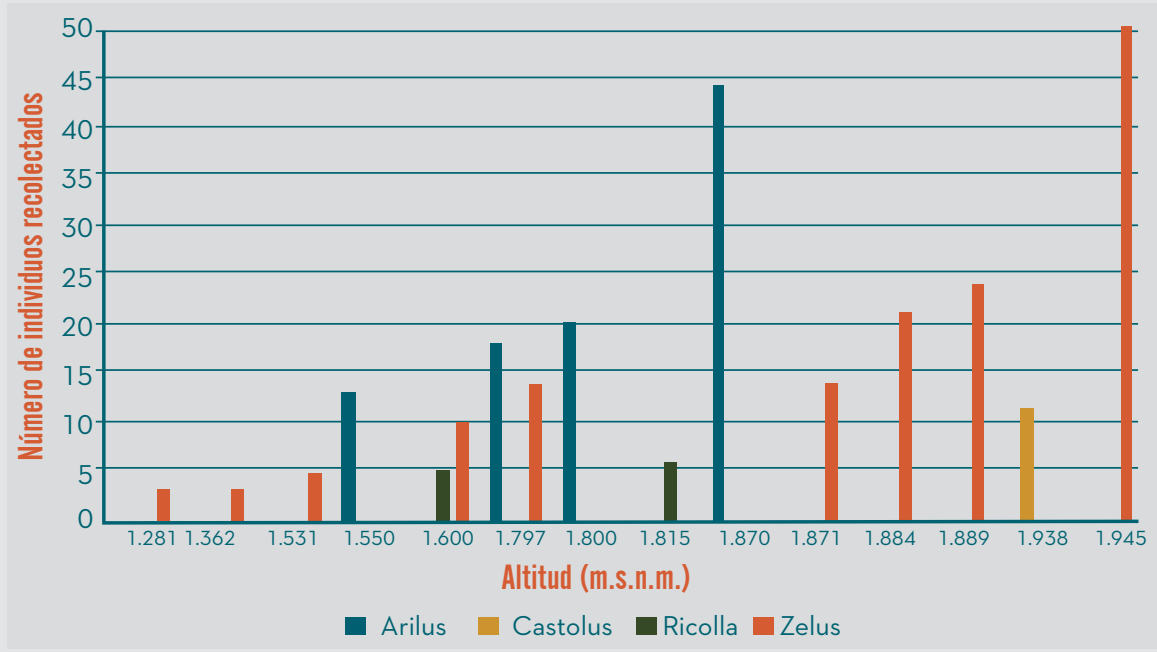

Figura 17.

Relación de individuos colectados

de Reduviidae por altitud en el

departamento del Huila.

(Bb9001, Bb9119, Bb9024), se obtuvieron los mayores porcentajes de mortalidad (93\%). Se observaron efectos tanto sinérgicos como antagónicos con respecto a la virulencia, siendo promisoria esta última combinación como alternativa para evaluar en el campo. Se confirmó mediante AFLP que las cepas pueden coinfectar el insecto. El uso de mezclas se evidenció como una alternativa en vez de la utilización de una sola cepa para el control del insecto y se abrió el espectro para el desarrollo futuro de formulaciones compuestas.

En el 2007 se evaluó la eficacia de estas mismas cepas y mezclas de cepas del hongo $B$. bassiana para el control del insecto en el campo; con este experimento se determinó nuevamente que la mezcla de cepas de baja virulencia (Bb9001, Bb9119, Bb9024), en pruebas de laboratorio, causabauna mortalidad de $100 \%$ sobre la broca del café, y en pruebas de campo, realizando infestaciones artificiales con el insecto en frutos de ramas de árboles, causaba en la broca una mortalidad de 66,6\% (Cárdenas et al., 2007). Desde el punto de vista biológico, una mortalidad cercana al 70\% sobre este insecto es un resultado importante que indica que es posible incrementar la eficacia del entomopatógeno.

Otro aspecto que se ha evaluado es el impacto de las brocas que emergen de los frutos brocados caídos al suelo en las futuras infestaciones de los frutos de la parte aérea de los árboles (Constantino, 2010). Siendo los frutos dejados en el suelo la fuente de infestación de los nuevos frutos en el árbol y ya que la cantidad de brocas depende de la temperatura, altitud y los períodos climáticos (Neutro, Evento La Niña o El Niño). Debido a esto, Vera et al. (2011) evaluaron en árboles individuales en el campo cubiertos por una jaula, el efecto de las cepas de $B$. bassiana sobre 50 frutos infestados dejados en el suelo y su impacto en la infestación de los frutos de la parte aérea de la planta, en dos Estaciones Experimentales de Cenicafé(Naranjal en Caldas y Paraguaicito en Quíndio) de la zona cafetera colombiana. Las cepas evaluadas fueron: $\mathrm{Bb}-9205$, la mezcla de cepas Cenicafé (Bb9001, Bb-9024 y Bb-9119) y una formulación comercial (Brocaril $\circledast$ ), asperjadas a una concentración de $1 \times 10^{9}$ conidias/ árbol, sobre 50 frutos infestados por plato de árbol. Al cabo de 30 días todas las cepas disminuyeron los niveles de infestación por broca en los árboles; la mezcla de cepas redujo la infestación entre un $50 \%$ y un $30 \%$ para ambas localidades. En los frutos disecados de cada árbol tratado la mortalidad estuvo por encima del $40 \%$, comparado con un $15 \%$ de mortalidad en el control sin aplicación del hongo. Las cepas de B. bassiana disminuyeron entre $55 \%$ y $75 \%$ las poblaciones de insectos dentro de los nuevos 
frutos infestados en la parte aérea, siendo la mezcla de cepas Cenicafé la más efectiva. Los resultados indicaron que $B$. bassiana disminuye significativamente la población de broca que emerge de frutos infestados del suelo y reduce las futuras generaciones del insecto.

Resultados similares fueron encontrados por Jaramillo et al. (2015) quienes validaron el efecto de la mezcla de cepas de $B$. bassiana y su combinación con $M$. anisopliae sobre la broca que emerge de frutos de café dejados en el suelo, se evaluó la virulencia de los hongos en el laboratorio, con los siguientes tratamientos aplicados: mezcla Cenicafé (Bb9001, Bb9024, Bb9119), M. anisopliae Ma9236, mezcla Cenicafé más Ma9236 y agua (testigo). Posteriormente, se establecieron tres parcelas en un cultivo comercial de café y en cada parcela se asignaron aleatoriamente los cuatro tratamientos, en grupos de 50 árboles. Cada 20 días y durante cuatro meses, se colocaron cuatro frutos brocados sobre el suelo de los árboles y luego se asperjaron con los tratamientos. Después de 18 días de cada aplicación, se evaluó la infestación y la población de brocas en los frutos infestados de los árboles. Adicionalmente, en el laboratorio, usando granos de café pergamino se determinó el efecto de las mezclas sobre la mortalidad y oviposición del insecto. En el laboratorio las cepas y las mezclas presentaron mortalidades sobre la broca entre el 91\% y el $94 \%$. En el campo, todos los tratamientos redujeron la infestación en los árboles entre el $18 \%$ y $47 \%$, respecto al testigo, obteniendo el máximo control con la mezcla Cenicafé con $M$. anisopliae; esta mezcla mantuvo porcentajes de broca en el lote inferiores al 6,6\% y disminuyó la población en los frutos infestados en un $40 \%$. En el laboratorio la mezcla Cenicafé afectó la capacidad de oviposición del insecto hasta en un $87 \%$.

Uno de los resultados más sobresalientes de este trabajo fue que los estudios de laboratorio (Figura 18) corroboraron las observaciones de campo, con respecto a la población de broca encontrada al interior de los frutos de cada tratamiento, lo que sugiere que las aplicaciones de hongos sobre frutos infestados del suelo, además de causar mortalidad sobre las brocas que volaron en busca de nuevos granos para infestar, causan disminución de la progenie de las broca infectadas que logran colonizar un fruto sano. Estos resultados muestran la importancia de las aplicaciones de hongos entomopatógenos dirigidas a frutos de café infestados del suelo como parte de un programa de manejo integrado, que busque mantener o reducir los niveles de la plaga en el cultivo.

\section{Ingeniería genética de hongos entomopatógenos}

En el caso del mejoramiento de los entomopatógenos los objetivos se han enfocado en reducir, tanto el tiempo que tarda el hongo en causar la muerte del insecto: Tiempo Letal (TL), como en poder utilizar un menor número de conidias, disminuyendo de
Figura 18.

Número promedio de estados de broca por fruto y por tratamiento en el laboratorio. Promedios con las mismas letras no son estadísticamente diferentes según la prueba de rangos múltiples de Duncan $(P=0,05)$. Sacado de Jaramillo et al 2015

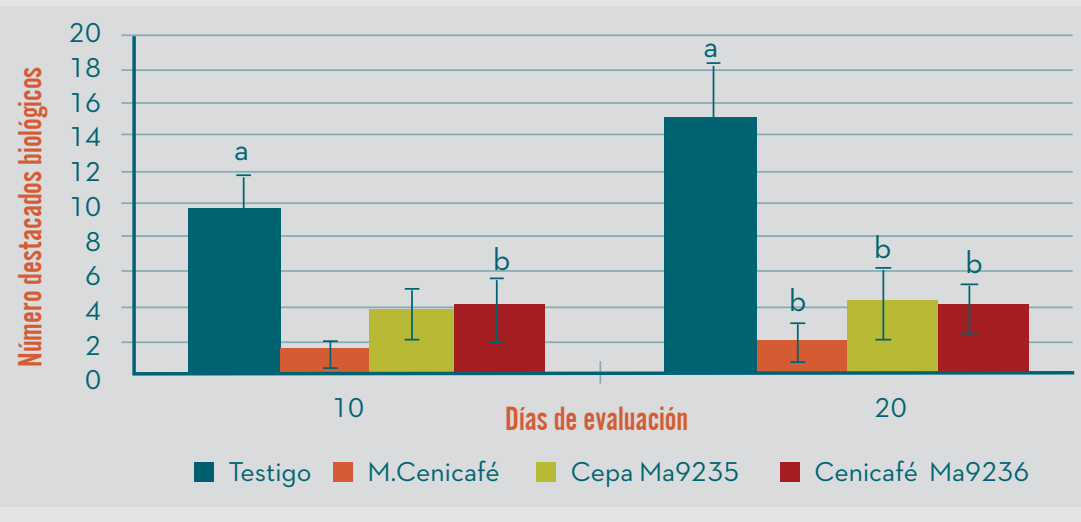


esta forma la concentración o dosis de hongo requerido: Dosis Letal (DL). El uso de una menor cantidad de conidias permitiría hacer un producto biológico desde el punto de vista económico más efectivo.

El mejoramiento de la virulencia se ha logrado a través del uso de modificación genética o ingeniería genética, de tal manera que el entomopatógeno pueda expresar proteínas dirigidas a afectar: la cutícula del insecto, las proteínas del insecto que afectan hormonas y su fisiología, péptidos neurotóxicos obtenidos de otros insectos predadores y otros patógenos de insectos y genes sintéticos (Lovett \& Leger, 2018). El segundo aspecto en el que se ha trabajo es en lograr la resistencia de los entomopatógenos a las condiciones ambientales adversas.

\section{Ingeniería de entomopatógenos para mejorar la virulencia}

A diferencia de los virus y las bacterias, los cuales tienen que ser ingeridos para causar enfermedad, los hongos entomopatógenos actúan como insecticidas de contacto, infectando a los insectos directamente a través de la cutícula. Los candidatos más atractivos inicialmente para hacer ingeniería genética y mejorar la virulencia incluyen enzimas degradadoras de la cutícula del insecto (proteasas y quitinasas) y toxinas que codifican genes únicos ya que son fáciles de manipular y de ser usados para hacer transferencias genéticas. Muchas de las enzimas degradadoras de cutícula, que actúan sinergísticamente para solubilizar las cutículas, son productos de múltiples genes con distintos patrones de actividad (St. Leger et al., 1996; Bagga et al., 2004). Además, estas moléculas tienen especialización patogénica que las distingue de otras moléculas similares pero producidas por organismos saprófitos. Por ejemplo, en el caso de la proteasa tipo subtilisina Pr1 obtenida de $M$. robertsii, esta presenta fuertes uniones contra proteínas insolubles presentes en la cutícula del insecto; debido a que los grupos de su superficie están cargados positivamente, y contribuyen a incrementar su actividad proteasa 33 veces más al ser comparada con la proteinasa $\mathrm{K}$ de saprófitos relacionados (St. Leger et al., 1992). La proteasa Pr1 es también resistente a inhibidores de proteinasas (serpinas) en la hemolinfa del insecto y a los sistemas de melanización rápida que simulan los mecanismos de defensa inmune del insecto (St. Leger et al., 1988).

En el primer ejemplo de un patógeno recombinante con un incremento en su virulencia, copias adicionales del gen que codifican la proteasa Pr1 fueron insertadas dentro del genoma de $M$. anisopliae, de tal forma que el gen se sobre expresaba constitutivamente (St. Leger et al., 1996). Al comienzo del experimento se esperaba que la sobre expresión de una proteasa degradadora de cutícula tuviera un efecto en la virulencia, acelerando la penetración de la cutícula del insecto; sin embargo, el efecto real de la sobre expresión fue el de causar una melanización masiva en el cuerpo del insecto y se detuvo el consumo de alimento 40 horas antes que en insectos infectados con un hongo no modificado. En contraste con las cepas no modificadas, la cepa transgénica produjo continuamente la proteasa Pr1 en el hemocele de las larvas de Manduca sexta luego de la penetración de la cutícula. Esto activó una enzima tipo tripsina en el insecto que está involucrada en una cascada metabólica del sistema inmune que terminó en la activación de la vía de profenoloxidación.

Los experimentos con microarreglos hoy en día, han mostrado que las cepas no transformadas de $M$. anisopliae detienen la expresión de los genes de proteasas en la hemolinfa del insecto, presumiblemente para prevenir este efecto de profenoloxidación (Wang, 2005). Un producto afortunado de esta interacción entre las proteasas del patógeno y las vías metabólicas de las fenoloxidasas del hospedante es que los insectos infectados con las cepas transgénicas y que muestran melanización extensiva, son muy pobres sustratos para el crecimiento del hongo y la esporulación. Esto reduce los procesos de transmisión y recombinación del hongo, siendo 
un obstáculo menos para la obtención de permisos para realizar evaluaciones de estos organismos en el campo (Hu \& Leger, 2002).

Con el objetivo de aumentar la patogenicidad de $B$. bassiana, en Cenicafé se determinó el efecto de la sobre expresión de genes involucrados en penetración de la cutícula de la broca del café. Para esto se sobre expresaron genes de proteasas tipo subtilisinas (pr1A, pr1J) y esterasa (ste1) aislados de $M$. anisopliae, en las cepas Bb 9011 y Bb9205 (Góngora, 2004). La expresión constitutiva de la proteasa en la cepa modificada Bb9205-pr1A mejoró su actividad insecticida al demostrar un incremento de mortalidad del $21,7 \%$, y una disminución del $14,3 \%$ en el tiempo de mortalidad sobre la broca del café. En tanto, el transformante Bb9205-ste1 disminuyó en un $9,5 \%$ el tiempo de mortalidad sobre broca al compararse con Bb9205 sin transformar (Rodríguez \& Góngora, 2005), esto demostró que la expresión de un gen patogénico de Metarhizium puede incrementar la virulencia en otra especie en este caso B. bassiana. De igual forma, la sobreexpresión de una esterasa de $M$. robertsii, un entomopatógeno generalista, en $M$. acridium especialista de Locus, permitió en este último expandir su rango de acción a Lepidópteros.

De igual modo, la sobre expresión de una quitinasa CHIT1 en $B$. bassiana causó reducción del tiempo de supervivencia del insecto blanco en 23\% y la combinación de sobre expresión de quitinasa y proteasa en $B$. bassiana logró reducir tanto el tiempo de muerte como la dosis letal en los insectos (Fang et al., 2009).

La proteasa subtilisina Pr1 fue clonada y estudiada con base en la hipótesis de que las enzimas degradadoras de la cutícula podrían ser requeridas para penetrar las barreras del hospedante. Recientemente basados en esta misma hipótesis la clonación de genes que se pensó que estaban involucrados en la patogenicidad ha sido reemplazada por el estudio de EST (Expressed Sequences Tag por sus siglas en inglés) y microarreglos que permite a los investigadores entender como un todo, el proceso de infección, además de permitir el estudio del patógeno durante este proceso (St. Leger, 2007). Estas técnicas permiten conocer los efectos secundarios o comportamientos de las cepas que han sido transformadas y tener un mayor rango de posibilidades de uso de la ingeniería genética, debido a que se ha ganado conocimiento con respecto a los procesos metabólicos, sus regulaciones y relaciones dentro de las células. Aunque estas técnicas aceleraron dramáticamente la obtención de información, la limitación está en convertir los patrones de expresión de genes en nuevas hipótesis, lo cual resulta en que claramente se identifique o compruebe la función de genes simples y se generen nuevas ideas para incrementar la virulencia.

En Cenicafé también se había venido trabajando en la identificación de los genes en $B$. bassiana involucrados en la virulencia del hongo frente a la broca del café. Es así como Mantilla et al. (2012) realizaron un estudio de expresión de genes en conidias y en micelios de $B$. bassiana atacando la broca, y secuenciaron dos librerías de EST. Se obtuvieron 4.186 secuencias de ADNc, y de su análisis se concluyó que la expresión de genes es diferente entre las conidias e hifas que invaden la cutícula del insecto. Esto explicaría las razones por las cuales la infección desarrollada por conidias es más eficientes que la observada por el micelio, ya que en estas se encontraron una elevada expresión de genes tales como los del tipo ciclofilina (relacionados con la formación del apresorio por parte del hongo), una serin proteasa alcalina (importante en el proceso de degradación de proteínas presentes en la cutícula), y una proteína quinasa activada por mitógenos (MAPK) (involucrada en unión y reconocimiento de la cutícula). Estos resultados tienen importantes implicaciones relacionadas con el adecuado momento de aspersión de los hongos sobre los insectos, y a la ventana de oportunidad de acción de las conidias. Para que estas sean efectivas deben germinar y penetrar prontamente al momento de entrar en contacto con la cutícula del insecto, siendo estas y no el micelio el que causa el mayor efecto sobre la broca. 
La sobre expresión de algunos de estos genes ha permitido el incremento de virulencia comparado con las cepas nativas con número reducido de copias. En Cenicafé se realizó un estudio para identificar diferencias con respecto a la expresión de genes en cepas con baja virulencia (Bb 9024) versus aquellas con alta virulencia (Bb9205), en donde se encontró que la cepa Bb 9024 produce menores cantidades de esterasas con respecto a la cepa más patogénica, por lo que el efecto en la cutícula del insecto es menor (Góngora et al., 2009). Adicionalmente, para determinar el efecto de una esterasa ste1, aislada de $M$. anisopliae en la virulencia de $B$. bassiana sobre la broca del café, se transformaron las cepas monospóricas Bb 9205 (con alta patogenicidad sobre broca) y Bb 9024 (con baja patogenicidad). Se seleccionaron los transformantes PCR positivos. Pruebas cualitativas de actividad esterolítica en el medio de cultivo tween 80 determinaron que Bb 9205 produce esterasas en baja cantidad y que Bb 9024 no produce esterasas detectables. Por su parte, los transformantes mostraron un incremento significativo de actividad esterolítica con respecto a los controles sin transformar. Evaluaciones de virulencia sobre la broca del café indican que en Bb9205.1.ste1.E62 no hay incrementos al compararla con $\mathrm{Bb} 9205$ sin transformar, mientras que en Bb9024.5.ste1.e15 y Bb9024.5.ste1.e45 se observa un incremento del $50 \%$ de virulencia con respecto a $\mathrm{Bb}$ 9024 sin transformar. En conclusión, las esterasas son un factor determinante para el incremento de la patogenicidad sobre la broca, en cepas con baja producción como la Bb9024, pero la sobre producción de esta enzima no tiene efecto patogénico en cepas de alta patogenicidad, con producciones relativamente altas y suficientes de esterasa (Góngora et al., 2006).

La generación de cepas de hongos con deleciones y silenciamiento de genes que están altamente expresados también ha permitido la identificación de diferentes proteínas: como es el caso de las adhesinas, las cuales son esenciales en la unión del hongo a la cutícula de los insectos y también a la superficie de las plantas (Wang \& St. Leger, 2007a), de la peripilina la cual regula la lipolisis, presión osmótica y la formación de estructuras de infección (Wang \& St. Leger, 2007b) y de un osmo sensor, que le indica a la hifa de penetración que ha alcanzado el hemocele (Wang et al., 2008). Todos estos genes tienen un potencial, que no se había identificado anteriormente, para hacer ingeniería con respecto al rango de los insectos hospedantes, incrementando o disminuyendo este potencial e ilustra el poder del estudio de los diferentes patrones de expresión, ya que muestra estrategias en los procesos de infección que no se esperaban previamente.

\section{Ingeniería de entomopatógenos por resistencia a condiciones ambientales}

La mayoría de estudios de patógenos de insectos se han enfocado en su virulencia. Sin embargo, si se espera que un patógeno funcione como un agente de biocontrol clásico y persista en el medio ambiente, entonces los factores que lo influencian incluirán un amplio rango de condiciones climáticas (radiación solar, temperatura, disponibilidad de agua, precipitaciones y viento), condiciones edáficas (tipos de suelo) y condiciones bióticas (antagonistas) (Inglis et al., 1997; Roberts \& St Leger, 2004). La resistencia con una base genética a estos parámetros podría ser una ventaja distintiva durante la infección, preparación del producto y el almacenamiento.

Los mecanismos genéticos de la resistencia a parámetros medioambientales no están bien entendidos, pero están probablemente gobernados por factores poligenéticos que pueden ser demasiado complejos para ser realmente factibles de manipulación genética. Sin embargo, se han obtenido progresos en el entendimiento de la susceptibilidad al daño por la porción solar del espectro de la luz UV-B (290-315 nm). 
Adicionalmente, el proceso de infección del hongo sobre la plaga es limitado por las condiciones ambientales, como la radiación UV. La radiación UV es una de los más complejos factores ambientales, ya que daña el ADN del hongo, causando mutaciones y mortalidad en el hongo. La exposición a radiación ultravioleta en hongos resulta en la formación de dímeros ciclobutano de pirimidina (CPD) en la molécula de ADN, responsables de mutaciones, inhibición en la germinación de conidias y retardo en crecimiento. La enzima encargada de reparar estos daños es la fotoliasa. En Cenicafé, con el propósito de mejorar la resistencia a la radiación UV en $B$. bassiana, se aisló y caracterizó el gen PHR1 que codifica la CPD fotoliasa, enzima que cataliza la reparación de CPDs (Rosero \& Góngora, 2007). El gen fue sobre expresado en la cepa $\mathrm{Bb}$ 9205. Las colonias fueron expuestas a luz UV-B, con una irradiancia de $1.200 \mathrm{mWalt} \mathrm{m}^{2}$ durante 0 , 1,2 y $3 \mathrm{~h}$. Se obtuvieron cepas que mostraron mayor resistencia a luz UVB comparadas con la cepa control, y mostraron porcentajes de viabilidad entre un $25 \%$ y $35 \%$ superiores. Dos de estas cepas se evaluaron por qPCR para cuantificar la expresión relativa del gen, usando micelio inducido en UV. Al comparar la expresión de la fotoliasa, las cepas presentaron mayor expresión en todos los tratamientos evaluados con respecto a la cepa control y su virulencia contra la broca se mantuvo (Córdoba et al., 2011; Góngora et al., 2015).

Fang \& St Leger (2012) realizaron estudios similares, en los que expresaron una fotoliasa aislada de Hobacterium altamente tolerante a UV, en M. robertsiiy B. bassiana, incrementando la supervivencia de estos hongos bajo luz solar más de 30 veces y manteniendo su virulencia contra Anopheles gambiae.

Adicionalmente, estudios han mostrado que el grado de pigmentación de las conidias y los niveles de enzimas de reparación de ADN contribuyen a la tolerancia a la luz UV y que existe una relación entre la tolerancia y el origen geográfico de los insectos hospedantes (Brags et al., 2006).

\section{Nuevas fuentes de genes para producir agentes biocontroladores transgénicos hipervirulentos}

Con el fin de desarrollar hongos recombinantes más potentes para el control de mosquitos, se pensó en combinar la habilidad natural de Metarhizium para penetrar el insecto con un péptido insecticida. Las toxinas mejor estudiadas de M. anisopliae son las destruxinas (Pal et al., 2007). Desafortunadamente para los propósitos de ingeniería genética, las destruxinas son metabolitos secundarios codificados por genes bastante grandes (ca20 $\mathrm{Kb})$ lo cual dificulta su manipulación genética. Un problema adicional que puede aparecer por usar genes propios del patógeno y toxinas para mejorar virulencia es que los hospedantes han tenido millones de años para evolucionar resistencia así que puede ser ventajoso tomar genes de toxinas de organismos heterólogos.

Las toxinas venenosas han mostrado un alto grado de especificidad y esto les permite ser consideradas estrategias medioambientalmente benignas para el manejo de insectos (Edwards \& Gatehouse, 2007). Sin embargo, ellas alcanzan sus receptores blancos únicamente cuando un escorpión pica a su presa y por sí sola no son capaces de penetrar la cutícula de los insectos. Por lo tanto, requieren un mecanismo que les permita llegar dentro del sistema circulatorio del insecto. La toxina de insecto 70 aa Androctonus australis (AalT) actúa a nivel de los canales de sodio neuronales, causando efectos excitatorios pre sinápticos y contracciones musculares a concentraciones muy bajas, nanomoles (Zlotkin et al., 2000). Estas toxinas han permitido desarrollar el más importante baculovirus recombinante evaluado en pruebas de campo (Sun et al., 2002).

Los alcances a los cuales la virulencia puede ser incrementada se mostraron al usar el promotor Mc/1 para expresar AalT en M. anisopliae (Wang \& St Leger, 2007). El hongo modificado alcanzó la misma tasa de mortalidad en el gusano cachón, $M$. sexta, con 
una dosis de 22 veces menos conidias que las cepas no transformadas, y los tiempos de supervivencia a algunas dosis se redujeron en $40 \%$. Se obtuvieron resultados similares en mosquitos (CL50 se redujo nueve veces) y en la broca del café (LC50 se redujo 16 veces) (Wang \& St Leger, 2007; Pava-Ripoll et al., 2008). A altas dosis de conidias la broca del café estaba muerta en menos de tres días y la dosis efectiva de conidias fue menos de cinco esporas. Sin embargo, las implicaciones medioambientales del uso de estas cepas debido a su especificidad y el efecto en organismos no blanco, son aun cuestionables.

\section{Selección de insectos depredadores como controladores biológicos}

Para definir una estrategia de control de plagas en el campo haciendo uso de parasitoides y depredadores como potenciales agentes de control, primero debe considerarse realizar estudios biológicos y ecológicos que permitan conocer el comportamiento del depredador a utilizar (Lucketal., 1988). Nicholls (2008) reporta una serie de atributos que son deseables en los enemigos naturales potenciales para ser incluidos dentro de programas de control biológico, entre ellos se encuentran: 1. Ser fáciles de criar en el laboratorio; 2. Alta sobrevivencia bajo condiciones de campo; 3. Alta capacidad de búsqueda para localizar el huésped o la presa; 4. Alta agregación en áreas con abundante densidad de la plaga, para disminuir su población a niveles que no causen daño; 5. Ser específicos y sincrónicos con el ciclo de vida de la plaga; 6. Capacidad para adaptarse al volumen de la plaga respondiendo rápidamente a posibles incrementos de la población bajo condiciones de estrés climático; 7. Mantenerse en el área aún después de que las poblaciones de la plaga hayan disminuido; 8. Su producción debe ser lo suficientemente económica para el agricultor. Sin embargo, estos atributos son más fácilmente alcanzados por los parasitoides que por los depredadores, debido a que los depredadores generalistas se consideran menos adecuados para el control biológico clásico, ya que presentan una menor tasa de reproducción y con frecuencia no están sincronizados con la plaga (Hajek, 2004). A pesar de ello, estudios demuestran que en el $75 \%$ de los casos los depredadores generalistas logran reducir significativamente las poblaciones de insectos plaga (Symondson et al., 2002).

Los depredadores tienen múltiples relaciones con su ecosistema. Las variables que más influyen en las interacciones entre los depredadores generalistas y sus presas son difíciles de predecir, debido a que ambos se encuentran dentro de múltiples sistemas de especies que están bajo la influencia de constantes cambios bióticos y abióticos (Symondson et al., 2002)

Para mejorar el control biológico ejercido por depredadores generalistas deben identificarse los factores que influyen entre las interacciones positivas y negativas dentro de las comunidades naturales en las que se encuentran y, de esta forma, optimizar las sinergias benéficas que conducen al control de plagas (Hajek, 2004).

El mejoramiento de la eficiencia de los depredadores para el control biológico de plagas debe iniciar con estudios de biología descriptiva, tanto del depredador como de la especie plaga a tratar. Los parámetros poblacionales del depredador arrojados por la tabla de vida de fertilidad determinan la capacidad de incremento de la población en el ecosistema después de la liberación (Luck et al., 1988). Para hacer uso de un depredador generalista, es ideal que presente bajas tasas de reproducción, pero que, a su vez, tenga la capacidad de mantener y regular su multiplicación en el ecosistema, de tal forma que la especie no pueda reproducirse a niveles que ocasionen más daños que beneficios en el cultivo después de una liberación. Es importante recalcar que la relación de los depredadores con las plagas, es dependiente de la densidad de estas últimas, ya que por ser de tipo generalista los depredadores, ante la ausencia de organismo blanco, se alimentarán de otra fuente alimenticia, lo cual podría llegar

El Control Natural de Insectos en el Ecosistema Cafetero Colombiano 
a generar desbalances ecológicos dentro del ecosistema y en algunos casos siendo nocivos (Kovach, 2004).

Los estudios de respuesta funcional de un depredador tienen como objetivo describir la relación entre el número de presas consumidas en función de la densidad poblacional de la presa, en un espacio e intervalo de tiempo (Solomon, 1949). La respuesta funcional es central para cualquier descripción sobre parasitismo o depredación, debido a que el número de presas consumidas determina el desarrollo, supervivencia y reproducción de los depredadores o parasitoides (Oaten \& Murdoch, 1975) y a su vez, sirve para evaluar su potencialidad como agente de control biológico de la plaga (Fernández \& Corley, 2003). Por lo tanto, la respuesta funcional junto con las características demográficas del depredador dadas por la tabla de vida, hacen parte de la base para definir el tipo de control biológico a implementar y con él, la cantidad y frecuencia de las liberaciones. El depredador, a diferencia del parasitoide, es un insecto generalista que puede llegar a afectar las poblaciones de organismos no blanco. En consecuencia, la cantidad de individuos liberados debe ser suficiente para permitir su establecimiento en el campo, pero sin poner en peligro la estabilidad de las especies no blanco nativas del ecosistema.

Considerando lo anterior, es indispensable identificar los riesgos asociados al uso de insectos depredadores como agentes de control biológico antes de realizar liberaciones en el campo abierto, dado que, además de desplazar especies como insectos benéficos (Hawkins \& Cornell, 2008), estos podrían producir molestias a comunidades humanas por aumentos exagerados de sus poblaciones (Kovach, 2004) o alimentarse de especies botánicas de interés económico (Trochez, 1987). En la actualidad, existen unos procedimientos básicos utilizados para definir las consecuencias indirectas de una liberación, entre los que se encuentran: el seguimiento de poblaciones no blanco antes y después de la liberación, utilizando un testigo sin el agente de control (Brown, 2003); estudios de campo confinado que incluyen los agentes de control biológico y un competidor (Schellhorn et al., 2002); pruebas de depredación intragremial en pequeñas arenas (Burgio et al., 2002); evaluaciones de establecimiento y dispersión del controlador biológico (Babendreier et al., 2005); estudios experimentales de modelación tipo Nicholson-Bailey para predecir riesgos potenciales del controlador (Lynch et al., 2002). Es de resaltar que la literatura reciente, a pesar de considerar los riesgos asociados a las liberaciones (Simberloff \& Stiling, 1996), también registra experiencias de impactos positivos con el uso de depredadores nativos como controladores biológicos (Kromp, 1999; Symondson et al., 2002).

El éxito del control biológico a implementar no solo depende de las características biológicas del depredador y de la planeación inicial de la estrategia, también depende de las condiciones en las que se va a mantener el ecosistema dentro del cafetal a liberar. Un ecosistema biológicamente equilibrado es aquel en donde se encuentra diversidad de insectos benéficos y de arvenses nobles. Se ha demostrado que algunas especies de Reduviidae depredadores complementan su dieta con la ingestión de néctar de las plantas, provenientes de flores y nectarios extra florales (Narbona \& Dirzo, 2010) y con la ingestión de savia, la cual extraen perforando el tejido de tallos y de hojas (Stoner et al., 1975a). Para algunas especies de Reduviidae, se sugiere que la ingestión de sustancias vegetales puede desempeñar un papel importante en la nutrición de las ninfas, las cuales pueden desarrollarse hasta la edad adulta alimentándose solo de estas (Stoner et al., 1975b), de igual forma, en las hembras estas sustancias parecen ser necesarias para sintetizar el material adhesivo que depositan en sus posturas (Choe \& Rust, 2007).

Los Reduviidae se consideran depredadores poco activos, debido a que desde los primeros estadios se alimentan y desarrollan cerca de las posturas de las cuales emergen y desde allí esperan a que aparezca una presa para consumirla sin ejercer una búsqueda activa de la misma (Santos et al., 2016). A pesar de 
ello, el desarrollo gregario de estas especies y su condición natural de depredadores genera una competencia por alimento que propicia el canibalismo, factor que influye en las bajas tasas de supervivencia ninfal (Grundy et al., 2000).

Los estudios que se están desarrollando en Cenicafé con insectos Reduviidae como depredadores para el control de la chinche de la chamusquina del café, han mostrado altas tasas de mortalidad de estos depredadores en sus primeros estadios ninfales bajo condiciones de laboratorio. Este comportamiento se asemeja al representado en la curva tipo IV de sobrevivencia de Rabinovich (1980), la cual se caracteriza por presentar mayor mortalidad natural de la especie en los estados inmaduros de la población. Desde la experiencia de Cenicafé, producir Reduviidae depredadores para utilizarlos en programas de control biológico ha representado un reto, debido a la alta necesidad de mano de obra y a la baja tasa de sobrevivencia ninfal.

Uno de los aspectos más importantes a considerar en la cría masiva de estos depredadores ha sido la fuente alimenticia a proporcionar. Utilizar una dieta adecuada para la cría de un depredador en condiciones de laboratorio, con alta calidad nutricional, juega un papel importante en el desarrollo morfológico y reproductivo de los individuos (Mayntz et al., 2005). Algunas dietas pueden lograr eficazmente la reproducción de los individuos, pero no necesariamente suplir todas sus necesidades nutricionales. Para evaluar la calidad de las dietas utilizadas en la producción de depredadores en masa suelen utilizarse parámetros biológicos como indicadores en la población tales como: la sobrevivencia ninfal, el tiempo de desarrollo, el tamaño de los adultos, la fecundidad, la viabilidad de los huevos, la razón sexual de la progenie y el tiempo de duplicación de la población (Cohen \& Urias, 1988). Durante el proceso de cría de Reduviidae en Cenicafé, se han observado cambios en la población que podrían indicar fallas en la metodología de cría de los individuos como: deformaciones morfológicas presentes en la segunda y tercera generación, cambios en la razón sexual, favoreciendo a los machos y mortalidad de las hembras oviplenas. Sin embargo, es importante considerar que la endogamia dentro una población criada en confinamiento también puede deteriorar la calidad de los individuos producidos (Clarke et al., 1986). Algunas observaciones hechas durante el proceso de cría de estos depredadores podrían indicar que los espacios confinados influyen en el comportamiento de cópula y reproductivo de las hembras. La saturación de hormonas en el ambiente podría explicar la alta mortalidad de hembras grávidas cuando se encuentran dentro de incubadoras con condiciones controladas; sin embargo, no existe información relacionada que valide tal hipótesis, más que los ensayos realizados en el laboratorio con hembras dentro y fuera de incubadoras.

A pesar de estas observaciones, los insectos han mostrado tener potencial como agentes de control de la chinche de la chamusquina del café (Cenicafé, 2017) y sus parámetros poblacionales los ponen como candidatos aptos para incluirlos dentro de programas de control biológico por aumentación y conservación.

\section{Nuevas técnicas de aplicación de entomopatógீenos}

Engeneral, los biopesticidasy entomopatógenos tienen algunos requerimientos para que afecten los insectos, como estar en contacto directo con la plaga, y a diferencia de los insecticidas de síntesis química, no dependen de la redistribución del producto y de la actividad translaminar o sistémica. Además, pueden aplicarse con equipos diseñados para la aspersión de insecticidas de síntesis química.

En parte el éxito de un entomopatógeno va a depender de las condiciones medioambientales al momento de la aplicación, tales como: temperatura, humedad relativa, $\mathrm{pH}$, la superficie en la que se aplica, al igual que la luz ultra violeta. Adicionalmente, 
un buen cubrimiento del biopesticida es esencial (Matthews, 2008); a menos que se utilicen atrayentes que lleven el insecto al biocontrolador o se combinen diferentes estrategias de control (atrayentes junto con entomopatógenos).

El proceso completo desde el descubrimiento del biocontrolador hasta la comercialización de cualquier ingrediente activo, sea microbiológico o agroquímico convencional, va a depender del éxito en el proceso de aspersión del producto. La forma de aplicación de un producto biológico es, por lo tanto, un componente clave para asegurar la eficacia del control por lo que no puede ser desatendido. Adicionalmente, las aspersiones van de la mano de otros componentes especialmente, las formulaciones, selección de cepas, mejoramiento y entendimiento del organismo blanco (Chapple et al., 2000).

Las aspersiones deben asegurar que la concentración de esporas o conidias en las gotas de agua sean suficientes para lograr aplicaciones inundativas, por lo tanto, se requieren dosis relativamente altas 2 a $4 \times 10^{10}$ esporas/L y en el caso de café, las cuantificaciones deben realizarse por número de árboles en la hectárea y no por hectárea ya que las densidades de siembra de los árboles de café son diferentes y pueden variar desde 2.000 hasta 10.000 árboles/ha.

Varios autores aseguran que los entomopatógenos deben aplicarse con máquinas hidráulicas, estas sirven para asperjar grandes volúmenes a baja presión, pero esto requiere mucha agua y hace ineficiente el sistema. El tamaño de gota también es importante, ya que si son muy pequeñas transportan pocas esporas (Chapple \& Bateman, 1997) o se taponan fácilmente, por lo que es necesario hacer pruebas para optimizar el tamaño de gota.

Varias de las nuevas técnicas de aplicación que han sido desarrolladas para hongos entomopatógenos involucran algún tipo de estación trampa, donde la persistencia efectiva es particularmente importante. Sin embargo, en el caso de la broca esta aproximación es algo complicada ya que el insecto estaría la mayor parte del ciclo de vida dentro del grano; sin embargo, si al momento de salir pudiera ser dirigido hacia las trampas este sería el momento para lograr que se infectara con el hongo.

Adicionalmente el uso de equipos con bajo volumen y el uso de tecnología tipo dron y aplicaciones de precisión para focos específicos de la plaga, ya sea agrupados naturalmente o dirigidos a estos, con el uso de plantas o sustancias atrayentes o repelentes, se convierten en alternativas a futuro que pueden hacer más efectivo el uso de los biocontroladores.

\section{Consideraciones finales}

Colombia es un país que se caracteriza por su alta diversidad biológica incluyendo biocontroladores. En el caso de las plagas endémicas del cultivo del café es posible su control a través del uso de biocontroladores por conservación. Sin embargo, para las plagas no nativas o introducidas, como la broca del café, la introducción de enemigos naturales y las aplicaciones inundativas de entomopatógenos como $B$. bassiana son estrategias que permiten reducir las poblaciones de insectos.

En el tema de la conservación, entre las influencias negativas que hacen más daño a las poblaciones de enemigos naturales están los pesticidas químicos, especialmente los de amplio espectro y efecto residual prolongado (Croft, 1990). Es por esta razón que en la caficultura colombiana estos pesticidas, especialmente los de la clase piretroides, no se han recomendado ya que las ventajas de su uso son menores que las desventajas.

El conocimiento de los enemigos naturales y sus necesidades es la mejor forma de conservarlos, es así como es indispensable crear y mantener los refugios de estos controladores, incrementar sus fuentes de alimentación que provean carbohidratos, así 
como cuidar y mantener sus hábitats. En el caso de los entomopatógenos, el mantener y conservar un cepario permite tener una fuente de biocontroladores para resolver los futuros problemas de la caficultura.

El hongo B. bassiana es el controlador por excelencia de la broca del café, si no estuviera presente, el daño de esta plaga en la caficultura colombiana sería mayor. Conocemos cepas que son altamente específicas y virulentas, contra la broca del café. El control del insecto usando este entomopatógeno es posible realizando aspersiones inundativas $\left(2 \times 10^{10}\right.$ conidias/L, y empleando hongos de excelente calidad y patogénicos contra el insecto.

El conocimiento de la interacción entomopatógeno-broca ha permitido el mejoramiento de la patogenicidad de las cepas a través del uso de la biología molecular y modificación de la expresión génica, se cuenta con cepas altamente selectivas y virulentas contra la broca. La combinación de diferentes cepas dentro del género $B$. bassiana y de diferentes géneros ( $B$. bassiana y Metarhizium) ha permitido hacer más eficiente el control de las plagas del café.

El conocimiento de la interacción de los entomopatógenos con el medio ambiente y los efectos de la luz UV, temperatura y humedad relativa permiten la creación y selección de cepas mejor adaptadas al medioambiente, en este aspecto las formulaciones de los hongos son fundamentales para lograr la mayor vida media y persistencia en el medio ambiente.

Para definir una estrategia de control de plagas en el campo, haciendo uso de parasitoides y depredadores como potenciales agentes de control, los estudios acerca de los aspectos biológicos, ecológicos y de comportamiento tanto de la plaga como del biocontrolador son fundamentales para asegurar el éxito de este último. Adicionalmente, la destrucción de refugios, lugares que brindan a los controladores resguardo y fuentes de alimentación, son prácticas negativas que deben evitarse ya que no permiten su establecimiento.

Es prioritario iniciar las evaluaciones de las sinergias de diferentes estrategias de control, combinando el uso de los entomopatógenos con extractos botánicos, entomopatógenos, depredadores y nuevos volátiles atrayentes o repelentes de las plagas del café y de sus depredadores, integrados a la agroecología, de tal manera que el control de las plagas del café sea cada vez más eficientes y amigables con el medio ambiente.

Es importante realizar evaluaciones que permitan conocer y cuantificar el riesgo ecológico de las estrategias de control biológico antes de ser implementadas, especialmente cuando se hace uso de depredadores y parasitoides como agentes de control. 


\section{Literatura citada}

Altre, J. A., \& Vandenberg, J. D. (2001). Penetration of Cuticle and Proliferation in Hemolymph by Paecilomyces fumosoroseus Isolates That Differ in Virulence against Lepidopteran Larvae. Journal of Invertebrate Pathology, 78(2), 81-86. https://doi.org/10.1006/jipa.2001.5046

Alves, S. B., Pereira, R. M., Lopes, R., \& Tamai, M. A. (2002). Use of Entomopathogenic Fungi in Latin America. In Advances in Microbial Control of Insect Pests (pp. 193-211). https://doi.org/10.1007/978-14757-4437-8 11

Babendreier, D., Bigler, F., \& Kuhlmann, U. (2005). Methods Used to Assess Non-target Effects of Invertebrate Biological Control Agents of Arthropod Pests. Biocontrol, 50, 821-870. https://doi.org/10.1007/ s10526-005-3633-3

Bagga, S., Hu, G., Screen, S. E., \& St Leger, R. J. (2004). Reconstructing the diversification of subtilisins in the pathogenic fungus Metarhizium anisopliae. Gene, 324, 159-169. https://doi.org/10.1016/j.gene.2003.09.031

Benavides Machado, P. (2008). Los parasitoides en programas de control biológico. In A. E. Bustillo Pardey (Ed.), Los insectos y su manejo en la caficultura colombiana (pp. 114-125).Cenicafé.

Bernal, M. G., Bustillo Parley, A. E., Chaves, B. C., \& Benavides Machado, P. (1999). Efecto de Beauveria bassiana y Metarhizium anisopliae sobre poblaciones de Hypothenemus hampei que emergen de frutos en el suelo. Revista Colombiana de Entomología, 25, 11-16.

Borges, M., \& Aldrich, J. R. (1992). Instar-specific defensive secretions of stink bugs (Heteroptera: Pentatomidae). Experientia, 48(9), 893-896. https://doi.org/10.1007/BF02118429

Brags, G. U. L., Rangel, D. E. N., Flint, S. D., Anderson, A. J., \& Roberts, D. W. (2006). Conidial Pigmentation Is Important to Tolerance Against Solar-simulated Radiation in the Entornopathogenic Fungus Metarhizium anisopliae. Photochemistry and Photobiology, 82(2), 418-422. https://doi.org/10.1562/2005-05-08-RA-52

Brown, M. W. (2003). Intraguild responses of aphid predators on apple to the invasion of an exotic species, Harmonia axyridis. BioControl, 48(2), 141-153. https://doi.org/10.1023/A:1022660005948

Burgio, G., Santi, F., \& Maini, S. (2002). On intra-guild predation and cannibalism in Harmonia axyridis (Pallas) and Adalia bipunctata L. (Coleoptera: Coccinellidae). Biological Control, 24(2), 110-116. https:/l doi.org/10.1016/S1049-9644(02)00023-3

Bustillo-Pardey, A. E., Bernal, M. G., Benavides Machado, P., \& Chaves, B. (1999). Dynamics of Beauveria bassiana and Metarhizium anisopliae Infecting Hypothenemus hampei (Coleoptera: Scolytidae) Populations Emerging from Fallen Coffee Berries. Florida Entomologist, 82(4), 491-498.

Bustillo-Pardey, A. E., Cárdenas, R., \& Posada, F. J. (2002). Natural Enemies and Competitors of Hypothenemus hampei (Ferrari) (Coleoptera: Scolytidae) in Colombia. Neotropical Entomology, 31(4), 635-639. https://doi.org/10.1590/S1519-566X2002000400018

Bustillo-Pardey, A. E. (2007). El manejo de cafetales y su relación con el control de la broca del café en Colombia. Boletín Técnico Cenicafé, 32, 1-40. http://hdl.handle.net/10778/579 
Bustillo-Pardey, A. E., Castillo, H., Villalba, D., Morales, E., \& Vélez, P. (1991, June 15). Evaluaciones de campo con el hongo Beauveria bassiana para el control de la broca del café [Conference session]. 14th International Scientific Colloquium on Coffee, San Francisco, USA.

Bustillo-Pardey, Á. E. (2002). Los hongos entomopatógenos en el control de insectos. En Curso Internacional Teórico -Práctico sobre entomopatógenos y parasitaoides que atacan la broca del café (pp. 1-53).

Butt, T. M., Coates, C. J., Dubovskiy, I. M., \& Ratcliffe, N. A. (2016). Entomopathogenic Fungi: New Insights into Host-Pathogen Interactions. Advances in Genetics, 94, 307-364. https://doi.org/10.1016/ bs.adgen.2016.01.006

Butt, T., Ibrahim, L., Clark, S. J., \& Beckett, A. (1995). The germination behaviour of Metarhizium anisopliae on the surface of aphid and flea beetle cuticles. Mycological Research, 99(8), 945-950. https:ll doi.org/10.1016/S0953-7562(09)80754-5

Cárdenas-Ramírez, Á., Villalba-Guott, D., Bustillo Pardey, Á. E., Montoya-Restrepo, E. C., \& Góngora, C. E. (2007). Eficacia de mezclas de cepas del hongo Beauveria bassiana en el control de la broca del café. Revista Cenicafé, 58(4), 293-303. http://hdl.handle.net/10778/140

Centro Nacional de Investigaciones de Cáfe. (2013). Informe anual Cenicafé 2013. https://www.cenicafe. org/es/publications/InformeAnual 2013.pdf

Centro Nacional de Investigaciones de Cáfe. (2016). Informe anual Cenicafé 2016. https://www.cenicafe. org/es/publications/InformeAnual2016.pdf

Centro Nacional de Investigaciones de Cáfe. (2017). Informe anual Cenicafé 2017. https://www.cenicafe. org/es/publications/Informe2017.pdf

Chapple, A. C., \& Bateman, R. P. (1997). Application systems for microbial pesticides: Necessity not novelty. In H. F. Evans (Ed.), Microbial insecticides: novelty or necessity? (pp. 181-190). British Crop Protection Council.

Chapple, A. C., Downer, R. A., \& Bateman, R. P. (2000). Theory and Practice of Microbial Insecticide Application. In L. A. Lacey \& H. K. Kaya (Eds.), Field Manual of Techniques in Invertebrate Pathology: Application and evaluation of pathogens for control of insects and other invertebrate pests (pp. 5-37). https://doi.org/10.1007/978-94-017-1547-8_2

Choe, D.-H., \& Rust, M. K. (2007). Use of Plant Resin by a Bee Assassin Bug, Apiomerus flaviventris (Hemiptera: Reduviidae). Annals of the Entomological Society of America, 100(2), 320-326. https://doi. org/10.1603/0013-8746(2007)100[320:UOPRBA]2.0.CO:2

Clarke, G. M., Brand, G. W., \& Whitten, M. J. (1986). Fluctuating Asymmetry: A Technique for Measuring Developmental Stress Caused by Inbreeding. Australian Journal of Biological Sciences, 39(2), 145-153. https://doi.org/10.1071/big860145

Cohen, A. C., \& Urias, N. M. (1988). Food utilization and egestion rates of the predator Geocoris punctipes (Hemiptera: Heteroptera) fed artificial diets with rutin. Journal of Entomological Science, 23(2), 174-179. https://doi.org/10.18474/0749-8004-23.2.174

Constantino, L. M. (2010). La broca del café... un insecto que se desarrolla de acuerdo con la temperatura y la altitud. Brocarta, 39, 1-2. https://www.cenicafe.org/es/publications/brc039.pdf 
Constantino, L. M., Gil-Palacio, Z., Benavides Machado, P., Martínez, H., Giraldo-Jaramillo, M., \& Villegas G., C. (2013). Otros habitantes naturales del cafetal. En Federación Nacional de Cafeteros de Colombia (Ed.), Manual del cafetero colombiano: investigación y tecnología para la sostenibilidad de la caficultura (Vol. 2, pp. 261-306). Cenicafé.

Córdoba, L. A., Mantilla, J. G., Montoya, E. C., \& Góngora Botero, C. E. (2011). Sobreexpresión de un gen de fotoliasa de Beauveria bassiana para evaluar su resistencia bajo condiciones de laboratorio a la luz UV-B. [Resumen de Congreso 38]. Sociedad Colombiana de Entomología.

Croft, B. A. (1990). Arthropod biological control agents and pesticides. John Wiley and Sons Inc.

Cruz, L. P., Gaitán, A. L., \& Góngora, C. E. (2006). Exploiting the genetic diversity of Beauveria bassiana for improving the biological control of the coffee berry borer through the use of strain mixtures. Applied Microbiology and Biotechnology, 71(6), 918-926. https://doi.org/10.1007/s00253-005-0218-0

David-Rueda, G., Constantino, L. M., Montoya, E. C., Ortega, O. E., Gil Palacio, Z. N., \& Benavides Machado, P. (2016). Diagnóstico de Leucoptera coffeella (Lepidoptera: Lyonetiidae) y sus parasitoides en el departamento de Antioquia, Colombia. Revista Colombiana de Entomología, 42(1), 4-11. https://doi. org/10.25100/socolen.v42i1.6662

Denoth, M., Frid, L., \& Myers, J. H. (2002). Multiple agents in biological control: improving the odds? Biological Control, 24(1), 20-30. https://doi.org/10.1016/S1049-9644(02)00002-6

Edwards, M. G., \& Gatehouse, A. M. (2007). Biotechnology in crop protection: Towards sustainable insect control. In M. Vurro \& J. Gressel (Eds.), Novel biotechnologies for biocontrol agent enhancement and management (pp. 1-23). Springer Netherlands. https://doi.org/10.1007/978-1-4020-5799-1 1

Fang, W., Feng, J., Fan, Y., Zhang, Y., Bidochka, M., St leger, R., \& Pei, Y. (2009). Expressing a fusion protein with protease and chitinase activities increases the virulence of the insect pathogen Beauveria bassiana. Journal of Invertebrate Pathology, 102(2), 155-159. https://doi.org/10.1016/i.jip.2009.07.013

Fang, W., \& St leger, R. J. S. (2012). Enhanced UV Resistance and Improved Killing of Malaria Mosquitoes by Photolyase Transgenic Entomopathogenic Fungi. PloS One, 7(8), e43069. https://doi.org/10.1371/ journal.pone.0043069

Fernández Arhex, V., \& Corley, J. (2003). The Functional Response of Parasitoids and its Implications for Biological Control. Biocontrol Science and Technology, 13(4), 403-413. https://doi. org/10.1080/0958315031000104523

Flaherty, D. L., \& Huffaker, C. B. (1970). Biological control of Pacific mites and Willamette mites in San Joaquin Valley vineyards: I. Role of Metaseiulus occidentalis. Hilgardia, 40(10), 267-308. https://doi. org/10.3733/hilg.v40n10p267

Follett, P. A., Kawabata, A., Nelson, R., Asmus, G., Burt, J., Goschke, K., Ewing, C., Gaertner, J., Brill, E., \& Geib, S. (2016). Predation by flat bark beetles (Coleoptera: Silvanidae and Laemophloeidae) on coffee berry borer (Coleoptera: Curculionidae) in Hawaii coffee. Biological Control, 101, 152-158. https:/l doi.org/10.1016/j.biocontrol.2016.07.002

Gil-Palacio, Z., Benavides Machado, P., \& Villegas-García, C. (2015). Manejo integrado de las cochinillas de las raíces del café. Avances Técnicos Cenicafé, 459, 1-8. http://hdl.handle.net/10778/637 
Giraldo-Jaramillo, M., Galindo-Leva, L. A., Benavides Machado, P., \& Forero, D. (2011). Aprenda a conocer las chinches depredadoras de plagas del café. Avances Técnicos Cenicafé, 412, 1-8. http://hdl. handle.net/10778/338

Goettel, M. S., Eilenberg, J., Glare, T., Lawrence, I. G., Kostas, I., \& Sarjeet, S. G. (2005). Comprehensive molecular insect science. Elsevier.

Góngora, C. E. (2011). ¿Cómo usar el hongo Beauveria bassiana para proteger su cosecha de café?. Brocarta, 42, 1-2. https://www.cenicafe.org/es/publications/brc042.pdf

Góngora, C. E., \& Benavides Machado, P. (2014). Pasado presente y futuro de la colección de hongos de Cenicafé. [Resumen de Congreso 41]. Sociedad Colombiana de Entomología.

Góngora, C. E., Cano, L. M., \& Ortega, M. A. (2006). Efecto de la expresión de esterasas en la patogenicidad de cepas transformadas de /Beauveria bassiana/ infectando la broca del café. [Resumen de Congreso 33]. Sociedad Colombiana de Entomología.

Góngora, C. E., \& Gil Palacio, Z. N. (2017). Control biológico de cochinillas Puto barberi Hemiptera: Putoidae en almácigos de café con hongos entomopatógenos. [Resumen de Congreso 44]. Sociedad Colombiana de Entomología.

Góngora, C. E., Marín-Marín, P., \& Benavides Machado, P. (2009). Claves para el éxito del hongo Beauveria bassiana como controlador biológico de la broca del café. Avances Técnicos Cenicafé, 384, 1-8. http://hdl.handle.net/10778/346

Góngora, C. E. (2008). Los hongos entomopatógenos en el control de insectos. In A. E. Bustillo Parley. (Ed.), Los insectos y su manejo en la caficultura colombiana (pp. 133-149). Cenicafé.

Góngora, C. E., Córdoba, L. A., \& Mantilla, J. G. (2015). Evaluación de cepas de Beauveria bassiana con tolerancia a luz UV y expresión relativa de fotoliasa. [Resumen de Congreso 42]. Sociedad Colombiana de Entomología.

Góngora, C. E. (2004). Transformación de Beauveria bassiana cepa Bb9112 con les genes de la proteína verde fluorescente y la protease pr1A de M. anisopliae. Revista Colombiana Entomología, 30, 15-21.

Hajek, A. E. (2004). Natural enemies: an introduction to biological control. Cambridge University Press.

Hassel, M. P. (1980). The Dynamics of Competition and Predation. Department of Zoology and Applied Entomology. Imperial College of Science and Technology, 72, 68.

Hawkins, B. A., \& Cornell, H. V. (2008). Theoretical approaches to biological control. Cambridge University Press.

Hu, G., \& Leger, R. J. S. (2002). Field Studies Using a Recombinant Mycoinsecticide (Metarhizium anisopliae) Reveal that It Is Rhizosphere Competent. Applied and Environmental Microbiology, 68(12), 6383-6387. https://doi.org/10.1128/AEM.68.12.6383-6387.2002

Imoulan, A., Hussain, M., Kirk, P., El Meziane, A., \& Yao, Y.-J. (2017). Entomopathogenic fungus Beauveria: Host specificity, ecology and significance of morpho-molecular characterization in accurate taxonomic classification. Journal of Asia-Pacific Entomology, 20(4), 1204-1212. https://doi.org/10.1016/j. aspen.2017.08.015 
Inglis, G. D., Johnson, D. L., Cheng, K.-J., \& Goettel, M. S. (1997). Use of Pathogen Combinations to Overcome the Constraints of Temperature on Entomopathogenic Hyphomycetes against Grasshoppers. Biological Control, 8(2), 143-152. https://doi.org/10.1006/bcon.1996.0495

Instituto Colombiano Agropecuario-ICA. (2004). Resolución 375 del 2004 por el cual se dictan las disposiciones sobre Registro y Control de los Bioinsumos y Extractos Vegetales de uso agrícola en Colombia. https://www.ica.gov.co/normatividad/normas-ica/resoluciones-oficinas-nacionales/resolucionesderogadas/resolucion-375-de-2004.aspx

Insuasty Burbano, O. I., Cuadros Martínez, J., Monroy Rodríguez, R., \& Bautista Díaz, J. (2007). Manejo integrado de moscas de la fruta de la guayaba (Anastrepha spp.) [Presentación]. Corpoica, Santander, Colombia. http://repository.agrosavia.co/handle/20.500.12324/2174

Jaramillo, J. L., Montoya Restrepo, E. C., \& Benavides Machado, P., Góngora, C. E. (2015). Beauveria bassiana y Metarhizium anisopliae para el control de broca del café en frutos del suelo. Revista Colombiana de Entomología, 41(1), 95-104.

Kovach, J. W. (2004). Impact of Multicolored Asian Lady Beetles as a Pest of Fruit and People. American Entomologist, 50(3), 159-161.

Kromp, B. (1999). Carabid Beetles in Sustainable Agriculture: a Review on Pest Control Efficacy, Cultivation Impacts and Enhancement. Agriculture, Ecosystems \& Environment, 74(1-3), 187-228. https:/l doi.org/10.1016/S0167-8809(99)00037-7

Laiton, L. A., Constantino, L. M., \& Benavides Machado, P. (2018). Capacidad depredadora de Cathartus quadricollis y Ahasverus advena (Coleoptera: Silvanidae) sobre Hypothenemus hampei (Coleoptera: Curculionidae) en laboratorio. Revista Colombiana de Entomología, 44(2), 200-205. https://doi.org/10.25100/ socolen.v44i2.7319

Lara G., J. C., López N., J. C., \& Bustillo-Parley, A. E. (2004). Efecto de entomonemátodos sobre poblaciones de la broca del café, Hypothenemus hampei (Coleoptera: Scolytidae), en frutos en el suelo. Revista Colombiana de Entomología, 30(2), 179-185.

Leger, R. S., Joshi, L., Bidochka, M. J., \& Roberts, D. W. (1996). Construction of an improved mycoinsecticide overexpressing a toxic protease. Proceedings of the National Academy of Sciences, 93(13), 6349-6354. https://doi.org/10.1073/pnas.93.13.6349

Lomer, C. J., Bateman, R., Johnson, D., Langewald, J., \& Thomas, M. (2001). Biological Control of Locusts and Grasshoppers. Annual Review of Entomology, 46(1), 667-702. https://doi.org/10.1146/annurev. ento.46.1.667

Lopes, R. B., Laumann, R. A., Blassioli-Moraes, M. C., Borges, M., \& Faria, M. (2015). The fungistatic and fungicidal effects of volatiles from metathoracic glands of soybean-attacking stink bugs (Heteroptera: Pentatomidae) on the entomopathogen Beauveria bassiana. Journal of Invertebrate Pathology, 132, 77-85. https://doi.org/10.1016/j.jip.2015.08.011

Lovett, B., \& Leger, R. J. S. (2018). Genetically engineering better fungal biopesticides. Pest Management Science, 74(4), 781-789. https://doi.org/10.1002/ps.4734

Luck, R. F., Shepard, B. M., \& Kenmore, P. E. (1988). Experimental Methods for Evaluating Arthropod Natural Enemies. Annual Review of Entomology, 33(1), 367-389. https://doi.org/10.1146/annurev. en.33.010188.002055 
Lynch, L. D., Ives, A. R., Waage, J. K., Hochberg, M. E., \& Thomas, M. B. (2002). The Risks of Biocontrol: Transient Impacts and Minimum Nontarget Densities. Ecological Applications, 12(6), 1872-1882. https:/l doi.org/10.1890/1051-0761(2002)012[1872:TROBTI]2.0.CO;2

Maldonado Capriles, J. (1990). Systematic catalogue of the Reduviidae of the world (Insecta: Heteroptera). University of Puerto Rico. https://catalog. hathitrust.org/Record/009172447

Maldonado, C. E., \& Benavides Machado, P. (2008). Evaluación del establecimiento de Cephalonomia stephanoderis y Prorops nasuta, controladores de Hypothenemus hampei, en Colombia. Revista Cenicafé, 58(4), 333-339. http://hdl.handle.net/10778/145

Mantilla, J. G., Galeano, N. F., Gaitan, A. L., Cristancho, M. A., Keyhani, N. O., \& Góngora, C. E. (2012). Transcriptome analysis of the entomopathogenic fungus Beauveria bassiana grown on cuticular extracts of the coffee berry borer (Hypothenemus hampel). Microbiology, 158(7), 1826-1842. https://doi.org/10.1099/ mic.0.051664-0

Matthews, G. (2008). Pesticide application methods. John Wiley \& Sons.

Mayntz, D., Raubenheimer, D., Salomon, M., Toft, S., \& Simpson, S. J. (2005). Nutrient-Specific Foraging in Invertebrate Predators. Science, 307(5706), 111-113. https://doi.org/10.1126/science.1105493

Milner, R. J. (1997). Insect pathogens: How effective are they against soil insect pests. Proceedings of the 3rd Brisbane Workshop on Soil Invertebrates, 63, 1-67.

Milner, R. J., \& Lutton, G. G. (1976). Metarrhizium anisopliae: survival of conidia in the soil. Proceedings of the International Colloquium on Invertebrate Pathology.

Narbona, E., \& Dirzo, R. (2010). A reassessment of the function of floral nectar in Croton suberosus (Euphorbiaceae): A reward for plant defenders and pollinators. American Journal of Botany, 97(4), 672679. https://doi.org/10.3732/ajb.0900259

Nicholls, C. I. (2008). Ecología de poblaciones como base teórica para el control biológico. In Control biológico de insectos: un enfoque agroecológico (pp. 11-19). Medellín, Colombia: Editorial Universidad de Antioquia.

Oaten, A., \& Murdoch, W. W. (1975). Switching, Functional Response, and Stability in Predator-Prey Systems. The American Naturalist, 109(967), 299-318. https://doi.org/10.1086/282999

Pal, S., St Leger, R. J., \& Wu, L. P. (2007). Fungal Peptide Destruxin A Plays a Specific Role in Suppressing the Innate Immune Response in Drosophila melanogaster. Journal of Biological Chemistry, 282(12), 89698977. https://doi.org/10.1074/jbc.M605927200

Pava-Ripoll, M., Posada, F. J., Momen, B., Wang, C., \& St. Leger, R. (2008). Increased pathogenicity against coffee berry borer, Hypothenemus hampei (Coleoptera: Curculionidae) by Metarhizium anisopliae expressing the scorpion toxin (AalT) gene. Journal of Invertebrate Pathology, 99(2), 220-226. https://doi. org/10.1016/i.jip.2008.05.004

Posada, F. (1997). Registro de hospedantes y aislamientos de beauveria bassiana en la colección de hongos entomopatógenos de Cenicafé. Colombia. Manejo Integrado de Plagas, 46, 50-64.

Posada, F. J., \& Bustillo-Parley, A. E. (1994). El hongo Beauveria bassiana y su impacto en la caficultura Colombiana. Agricultura Tropical, 31(3), 97-106. 
Rabinovich, J. E. (1980). Introducción a la ecología de poblaciones animales. Compañía Editorial Continental.

Ramírez-Cortés, H. J., Gil-Palacio, Z., Benavides Machado, P., \& Bustillo-Pardey, Á. E. (2008). Monalonion velezangeli La chinche de la chamusquina del cafe. Avances Técnicos Cenicafé, 367, 1-8. http://hdl. handle.net/10778/392

Roberts, D. W., \& St Leger, R. J. (2004). Metarhizium spp., cosmopolitan insect-pathogenic fungi: mycological aspects. Advances in Applied Microbiology, 54(1), 1-70. https://doi.org/10.1016/S00652164(04)54001-7

Rodríguez, M. L., \& Góngora, C. E. (2005). Tansformation of Beauveria bassiana Bb9205 with pr1A, pr1J, and ste1 genes of Metartzizium anisopliae and evaluation of the pathogenicity on the coffee berry borer. Revista Colombiana de Entomología, 31(1), 51-58.

Romoser, W. S., \& Stoffolano, J. G. (1998). The science of entomology (4th ed).WCB McGraw-Hil

Rosero, L. C., \& Góngora, C. E. (2007). Caracterización y aislamiento de un gen defotoliasa del hongo entomopatógeno Beauveria bassiana. [Resumen de Congreso 34]. Sociedad Colombiana de Entomología.

Santos Murgas, A., Abrego, J. C., Añino, Y., \& López, O. G. (2016). Notas sobre depredación de Apiomerus hirtipes (Hemiptera: Reduviidae) sobre abejas de la orquídea (Apidae: Euglossinae). Revista Científica Centros, 5(2), 46-52.

Sasan, R. K., \& Bidochka, M. J. (2012). The insect-pathogenic fungus Metarhizium robertsii(Clavicipitaceae) is also an endophyte that stimulates plant root development. American Journal of Botany, 99(1), 101-107. https://doi.org/10.3732/ajb.1100136

Schellhorn, N. A., Kuhman, T. R., Olson, A. C., \& Ives, A. R. (2002). Competition between Native and Introduced Parasitoids of Aphids: Nontarget Effects and Biological Control. Ecology, 83(10), 2745. https:/l doi.org/10.2307/3072012

Schrank, A., \& Vainstein, M. H. (2010). Metarhizium anisopliae enzymes and toxins. Toxicon, 56(7), $1267-$ 1274. https://doi.org/10.1016/j.toxicon.2010.03.008

Shapiro-Ilan, D. I., Fuxa, J. R., Lacey, L. A., Onstad, D. W., \& Kaya, H. K. (2005). Definitions of pathogenicity and virulence in invertebrate pathology. Journal of Invertebrate Pathology, 88(1), 1-7. https:ll doi.org/10.1016/j.jip.2004.10.003

Simberloff, D., \& Stiling, P. (1996). How Risky is Biological Control?. Ecology, 77(7), 1965-1974. https://doi.org/10.2307/2265693

Solomon, M. E. (1949). The Natural Control of Animal Populations. The Journal of Animal Ecology, 18(1), 1. https://doi.org/10.2307/1578

St. Leger, R. (2007). Metarhizium anisopliae as a model for studying bioinsecticidal host pathogen interactions. In M. Vurro \& J. Gressel (Eds.), Novel Biotechnologies for Biocontrol Agent Enhancement and Management (pp. 179-204). Springer Netherlands.

St. Leger, R., Cooper, R. M., \& Charnley, A. K. (1988). The effect of melanization of Manduca sexta cuticle on growth and infection by Metarhizium anisopliae. Journal of Invertebrate Pathology, 52(3), 459-470. https://doi.org/10.1016/0022-2011(88)90059-6 
St. Leger, R., Frank, D. C., Roberts, D. W., \& Staples, R. C. (1992). Molecular cloning and regulatory analysis of the cuticle-degrading-protease structural gene from the entomopathogenic fungus Metarhizium anisopliae. European Journal of Biochemistry, 204(3), 991-1001. https://doi.org/10.1111/j.1432-1033.1992. tb 16721.x

StLeger, R. J., Joshi, L., Bidochka, M. J., Rizzo, N. W., \& Roberts, D. W. (1996). Biochemical characterization and ultrastructural localization of two extracellular trypsins produced by Metarhizium anisopliae in infected insect cuticles. Applied and Environmental Microbiology, 62(4), 1257-1264.

St. Leger, R., Joshi, L., Bidochka, M., Rizzo, N. W., \& Roberts, D. W. (1996). Characterization and Ultrastructural Localization of Chitinases from Metarhizium anisopliae, M. flavoviride, and Beauveria bassiana during Fungal Invasion of Host (Manduca sexta) Cuticle. Applied and Environmental Microbiology, 62(3), 907-912.

Stoner, A., Metcalfe, A. M., \& Weeks, R. E. (1975). Plant feeding by Reduviidae, a predaceous family (Hemiptera). Journal of the Kansas Entomological Society, 48(2), 185-188.

Sun, X., Chen, X., Zhang, Z., Wang, H., Bianchi, F. J. J. A., Peng, H., Vlak, J. M., \& Hu, Z. (2002). Bollworm responses to release of genetically modified Helicoverpa armigera nucleopolyhedroviruses in cotton. Journal of Invertebrate Pathology, 81(2), 63-69. https://doi.org/10.1016/S0022-2011(02)00144-1

Sweetman, H. L. (1958). The principles of biological control. Wm C Brown Company Publishers.

Symondson, W. O. C., Sunderland, K. D. T., \& Greenstone, M. H. (2002). Can generalist predators be effective biocontrol agents? Annual Review of Entomology, 47(1), 561-594. https://doi.org/10.1146/annurev. ento.47.091201.145240

Tanada, Y., \& Kaya, H. (1993). Insect Pathology. Academic Press.

Trochez, A. (1987). Manual de reconocimiento de insectos asociados en productos almacenados Adolfo Trochez. IICA. https://repository.agrosavia.co/handle/20.500.12324/13128

Van Driesche, R., \& Bellows Jr, T. (1996). Biological Control. Springer US. https://doi.org/10.1007/978-14613-1157-7

Vélez, P. E., Posada, F. J., Marín, P., González, M. T., Osorio, E., \& Bustillo-Parley, A. E. (1997). Técnicas para el control de calidad de formulaciones de hongos entomopatógenos. Boletín Técnico Cenicafé, 17, 1-37. http://hdl.handle.net/10778/709

Vélez Arango, P. E., \& Benavides Gómez, M. (1990). Registro e identificación de Beauveria bassiana en Hypothenemus hampei en Ancuya, Departamento de Nariño, Colombia. Revista Cenicafé, 41(2), 50-57. http://hdl.handle.net/10778/4167

Vera, J. T., Montoya, E. C., Benavides Machado, P., \& Góngora, C. E. (2011). Evaluation of Beauveria bassiana (Ascomycota: Hypocreales) as a control of the coffee berry borer Hypothenemus hampei (Coleoptera: Curculionidae: Scolytinae) emerging from fallen, infested coffee berries on the ground. Biocontrol Science and Technology, 21(1), 1-14. https://doi.org/10.1080/09583157.2010.517605

Vera-Montoya, L., Gil-Palacio, Z., \& Benavides Machado, P. (2007). Identificación de enemigos naturales de Hypothenemus hampei en la zona cafetera central colombiana. Revista Cenicafé, 58(3), 185-195. http:/l hdl. handle.net/10778/144 
Wang, C., Duan, Z., \& St. Leger, R. J. (2008). MOS1 Osmosensor of Metarhizium anisopliae Is Required for Adaptation to Insect Host Hemolymph. Eukaryotic Cell, 7(2), 302-309. https://doi.org/10.1128/EC.00310-07

Wang, C., Hu, G., \& St. Leger, R. J. (2005). Differential gene expression by Metarhizium anisopliae growing in root exudate and host (Manduca sexta) cuticle or hemolymph reveals mechanisms of physiological adaptation. Fungal Genetics and Biology, 42(8), 704-718. https://doi.org/10.1016/j.fgb.2005.04.006

Wang, C., \& St Leger, R. J. (2007). A scorpion neurotoxin increases the potency of a fungal insecticide. Nature Biotechnology, 25(12), 1455-1456. https://doi.org/10.1038/nbt1357

Wang, C., \& St. Leger, R. J. (2007a). The MAD1 Adhesin of Metarhizium anisopliae Links Adhesion with Blastospore Production and Virulence to Insects, and the MAD2 Adhesin Enables Attachment to Plants. Eukaryotic Cell, 6(5), 808-816. https://doi.org/10.1128/EC.00409-06

Wang, C., \& St. Leger, R. J. (2007b). The Metarhizium anisopliae Perilipin Homolog MPL1 Regulates Lipid Metabolism, Appressorial Turgor Pressure, and Virulence. Journal of Biological Chemistry, 282(29), 21110-21115. https://doi.org/10.1074/jbc.M609592200

Wille, A., \& Fuentes, G. (1975). Efecto de la ceniza del Volcán: Irazú (Costa Rica) en algunos insectos. Revista de Biología Tropical, 23(2), 165-175.

Zhang, G., Hart, E. R., \& Weirauch, C. (2016). A taxonomic monograph of the assassin bug genus Zelus Fabricius (Hemiptera: Reduviidae): 71 species based on 10,000 specimens. Biodiversity Data Journal, 4, e8150. https://doi.org/10.3897/BDJ.4.e8150

Zhang, S., Xia, Y. X., Kim, B., \& Keyhani, N. O. (2011). Two hydrophobins are involved in fungal spore coat rodlet layer assembly and each play distinct roles in surface interactions, development and pathogenesis in the entomopathogenic fungus, Beauveria bassiana. Molecular Microbiology, 80(3), 811-826. https://doi. org/10.1111/j.1365-2958.2011.07613.x

Zlotkin, E., Fishman, Y., \& Elazar, M. (2000). AalT: From neurotoxin to insecticide. Biochimie, 82(9), 869881. https://doi.org/10.1016/S0300-9084(00)01177-9

Como Citar:

Góngora, C. E., \& Laiton-Jiménez, L. A. (2020). Control biológico en las plagas de café de Colombia. En P. Benavides Machado \& C. E. Góngora (Eds.), El Control Natural de Insectos en el Ecosistema Cafetero Colombiano (pp. 68-104). Cenicafé. https://doi.org/10.38141/10791/0001 4 